\title{
Development and genetics of red coloration in the zebrafish relative Danio albolineatus
}

\author{
Delai Huang1, Victor M. Lewis ${ }^{1 *}$, Matthew B. Toomey²,3, Joseph C. Corbo ${ }^{3}$, \\ David M. Parichy ${ }^{1,4}$
}

1 Department of Biology, University of Virginia, Charlottesville, United States

2 Department of Biological Science University of Tulsa, Tulsa, United States

3 Department of Pathology and Immunology, Washington University School of Medicine, St. Louis, United States

${ }^{4}$ Department of Cell Biology, University of Virginia, Charlottesville, United States

For correspondence: dparichy@virginia.edu (DMP)

* Present address: Institute of Molecular Biology, University of Oregon, Eugene, United States 


\begin{abstract}
Animal pigment patterns play important roles in behavior and, in many species, red coloration serves as an honest signal of individual quality in mate choice. Among Danio fishes, some species develop erythrophores, pigment cells that contain red ketocarotenoids, whereas other species, like zebrafish ( $D$. rerio) only have yellow xanthophores. Here, we use pearl danio $(D$. albolineatus) to assess the developmental origin of erythrophores and their mechanisms of differentiation. We show that erythrophores in the fin of $D$. albolineatus share a common progenitor with xanthophores and maintain plasticity in cell fate even after differentiation. We further identify the predominant ketocarotenoids that confer red coloration to erythrophores and use reverse genetics to pinpoint genes required for the differentiation and maintenance of these cells. Our analyses are a first step towards defining the mechanisms underlying the development of erythrophore-mediated red coloration in Danio and reveal striking parallels with the mechanism of red coloration in birds.
\end{abstract}

\title{
Introduction
}

Red and orange pigments deposited in the skin provide key signals that are subject to sexual or natural selection. For example, the intensity of red or orange coloration, or the area over which it occurs, has been associated with mating preferences in a variety of species (Milinski and Bakker, 1990; Hill, 1991; Houde, 1997; Grether, 2000; Takahashi, 2018) and in some cases the very conspicuousness that makes an individual attractive can make it more vulnerable to predators (Endler, 1980; Godin and McDonough, 2003; Johnson and Candolin, 2017). Red or orange coloration can also be associated with aggressive interactions (Evans and Norris, 1996; Pryke and Griffith, 2006; Dijkstra et al., 2009) and warning coloration (Brodie and Brodie, 1980; Stevens and Ruxton, 2012).

Red, orange, and yellow coloration is often mediated by the accumulation of carotenoids, fat-soluble compounds that are synthesized by plants and some fungi and bacteria, and obtained by animals via their diet and then subsequently modified (Bagnara and Matsumoto, 2006; McGraw, 2006; Svensson and Wong, 2011; Sefc et al., 2014; Strange, 2016; Toews et al., 2017). More than a thousand naturally occurring carotenoids are known, and their basic structure consists of 40 carbon atoms derived from four terpene molecules (Figure 1A).

Carotenoids contain a system of conjugated double bonds that absorb light in the visible range; the greater the length of the conjugated system, the more red-shifted the absorption. Yellow carotenoids, such as $\beta$-carotene or zeaxanthin, have a total of 11 conjugated double bonds, whereas red carotenoids, such as astaxanthin, have a total of 13 due to the addition of ketone groups in the 4 and 4' positions of the terminal rings of the molecule (Figure 1A). Many animal species possess endogenous "ketolase" activity, and thus can add ketones to diet-derived yellow carotenoids to produce red ketocarotenoids. The final color displayed by an animal reflects the specific carotenoids absorbed in the gut, transported to peripheral tissues, and chemically modified to achieve specific light-absorptive properties. Carotenoids also have important functions as vitamin A precursors, as antioxidants, and as regulators of a variety of cellular functions. The multifunctionality of carotenoids, and the need to obtain them from the environment, have contributed to the notion that carotenoids in the integument can serve as an honest signal of prospective fitness, to mates or rivals (Endler, 1980; Weaver et al., 2017; Weaver et al., 2018). 
The cellular context for displaying carotenoid-dependent colors differs between endothermic and ectothermic vertebrates. In birds, carotenoids are concentrated in keratinocytes of the skin and displayed either directly or after incorporation into feathers (McGraw, 2006). In ectotherms, carotenoids are concentrated in lipid droplets within pigment cells, chromatophores, visible through the epidermis and dermis. Red chromatophores are known as erythrophores, whereas yellow or orange chromatophores are referred to as xanthophores. Besides accumulating carotenoids, both cell types can produce and retain pteridine pigments that sometimes also contribute to visible coloration (Schartl et al., 2016; Parichy, 2021).

Erythrophores and xanthophores, like other skin chromatophores-black melanophores, iridescent iridophores, and white leucophores-develop from embryonic neural crest cells, either directly, or indirectly, via latent progenitors in the peripheral nervous system or other tissue compartments (Kelsh et al., 2009; Patterson and Parichy, 2019). Though sharing a common cell lineage overall, the degree to which different chromatophore types share faterestricted progenitors remains incompletely understood. In zebrafish for example, most xanthophores on the body differentiate as pteridine-containing xanthophores in the embryo, then proliferate and lose their color, only to reacquire carotenoid-dependent coloration in the adult; other xanthophores on the body and in the fin develop instead from latent progenitors (Tu and Johnson, 2011; McMenamin et al., 2014; Singh et al., 2016; Saunders et al., 2019). By contrast, the majority of adult iridophores and melanophores develop from a common progenitor in the peripheral nervous system (Budi et al., 2011; Dooley et al., 2013; Singh et al., 2016). Lineage relationships can be further complicated by direct transitions between chromatophore types. Such transitions have long been known to be inducible experimentally (Niu, 1954; Ide and Hama, 1976), but have also been found naturally in zebrafish, in which a class of fin leucophore develops directly from melanophores (Lewis et al., 2019).

With respect to red coloration, the lineage relationship of erythrophores to xanthophores is not known. Though studies across several species have revealed both similarities and differences in cytological appearance and pigment biochemistry (Matsumoto, 1965; Matsumoto and Obika, 1968; Ichikawa et al., 1998; Khoo et al., 2012; Djurdjevic et al., 2015), it remains unclear if erythrophores share a progenitor with xanthophores, or whether they might develop directly from xanthophores. Likewise, the genes required for red coloration, as opposed to orange or yellow coloration, remain largely unexplored, though two loci required for, or associated with, ketocarotenoid accumulation, have been identified in birds (Eriksson et al., 2008; Lopes et al., 2016; Mundy et al., 2016; Toomey et al., 2017; Toomey et al., 2018).

Here, we exploit the presence of erythrophores in a zebrafish relative, the pearl danio Danio albolineatus, to interrogate cell lineage relationships between erythrophores and xanthophores, and to identify genes essential for red and orange coloration in this species. By clonal analysis and fate mapping we show that early erythrophores and xanthophores of the fin arise from a common, initially orange progenitor, the descendants of which adopt one or the other fate depending on their location. We further show that later-arising erythrophores and xanthophores of the fin develop directly from unpigmented precursors, and that transitions between erythrophore and xanthophore states can occur during regeneration. By screening candidate genes identified through transcriptomic comparisons of erythrophore- and xanthophorecontaining fin tissues, we additionally demonstrate requirements for several genes in red or yellow coloration. These include loci encoding a cytochrome P450 monooxygenase, belonging to the same protein family as an enzyme previously implicated in avian red coloration (Lopes et al., 2016), as well as two genes not previously implicated in red coloration. These results lay the groundwork for future biochemical analyses of carotenoid processing, dissection of mechanisms 
of erythrophore fate specification, and comparative analyses of species-specific losses or gains of erythrophore-dependent coloration.

\section{Results}

\section{Phylogenetic distribution of erythrophores in Danio and patterning of erythrophores and xanthophores in the anal fin of $D$. albolineatus}

The adult zebrafish (Danio rerio) pigment pattern includes yellow xanthophores, black melanophores, at least three types of iridescent iridophores, and two types of white cells (melanoleucophores and xantholeucophores) (Hirata et al., 2003; Lewis et al., 2019; Patterson and Parichy, 2019; Gur et al., 2020). Zebrafish does not have red erythrophores. Because erythrophores occur in many other species of teleosts, we surveyed the distribution of these cells across the Danio genus more broadly. Of 17 Danio species assessed, 14 had erythrophores indicating this cell type is common and most likely was present in the common ancestor of all Danio species (Figure 1B-D).

We focused on $D$. albolineatus as erythrophores were abundant in this species and are separated spatially from other pigment cells, an arrangement likely to facilitate analysis (Goodrich and Greene, 1959). In the anal fin of adults, red erythrophores were located proximally and were separated from the more distal yellow xanthophores by a narrow stripe of melanophores (Figure $\mathbf{2 A}$ ). Although erythrophores were present in both sexes, the cells were more deeply and consistently red in males than females and we therefore focused on males at stages when sexes were distinguishable (Figure 2-figure supplement 1A). Male fish older than one year often lacked fin stripe melanophores, indicating that some pattern remodeling continues even after sexual maturation (Figure 2-figure supplement 1B). As compared to xanthophores, erythrophores occur at lower densities and were more likely to be binucleated (Figure 2B, middle and right panels; Figure 2-figure supplement 1C and 1D), a characteristic associated with a mature state of differentiation in stripe melanophores of zebrafish (Saunders et al., 2019).

Because subtle differences in color can be difficult to discern, we sought metrics to describe mature and developing cells, under brightfield and fluorescent illumination in which these cells were distinguishable as well: xanthophores autofluoresced with a green excitation wavelength $(488 \mathrm{~nm})$ owing to the presence of carotenoids (Granneman et al., 2017; Saunders et al., 2019), whereas erythrophores autofluoresced only weakly at this wavelength but strongly under a red wavelength (561 nm)(Figure 2 C). We therefore quantified hue in brightfield illumination and relative red:green signals of autofluorescence, which confirmed the distinct locations of erythrophores and xanthophores in these color spaces (Figure 2D and 2E).

To understand the anatomical context of erythrophore development, we imaged fish during the larva-to-adult transformation. The first pigmented cells in the anal fin were lightly melanized melanophores. Subsequently, orange xanthophore-like cells appear that were pale and had smaller areas of visible pigment than mature erythrophores and xanthophores (Figure 2B, left panel; Figure 2-figure supplement 2). These early orange cells autofluoresced in both red and green channels, consistent with their appearance in brightfield (Figure 2F). During later development, however, cells in proximal regions were increasingly red whereas cells in distal regions were increasingly yellow. Cell densities gradually diverged between proximal and distal regions as well (Figure 2F; Figure 2-figure supplement 1D). 


\section{Fin erythrophores and xanthophores arise from a common progenitor}

As a first step in dissecting lineage relationships of erythrophores and xanthophores we sought to determine whether these cells arise from a common early progenitor. Since red and yellow colors were likely carotenoid-based, we reasoned that lineage relationships should be revealed by clones of cells in fish mosaic for scavenger receptor b1 (scarb1), which is essential for carotenoid accumulation in avian integument and zebrafish xanthophores (Toews et al., 2017; Toomey et al., 2017; Saunders et al., 2019). If erythrophores and xanthophores share a lineage, then rare wild-type clones should contain both red and yellow cells in an otherwise colorless background. If erythrophores and xanthophores have distinct lineage origins, however, wild-type clones should often contain only red cells or only yellow cells. In $D$. albolineatus injected with high efficiency AltR CRISPR/Cas9 reagents targeting scarb1, wild-type clones most often contain both red cells and yellow cells (Figure $3 A$ ).

We further assessed relationships by labeling individual clonal lineages by tol 2 transgenesis. We found that orange cells of larvae and both erythrophores and xanthophores of adults expressed transgenes driven by regulatory elements of aldehyde oxidase 5 (aox5) isolated from zebrafish. aox 5 functions in the synthesis of pteridines present in xanthophores and erythrophores (see below) and is expressed by xanthophores and their specified precursors in zebrafish (Parichy et al., 2000; McMenamin et al., 2014). When we injected an aox5 reporter transgene at limiting dilutions to express membrane-targeted EGFP, labeled cells were restricted to narrow regions along the anterior-posterior axis, consistent with derivation from single clones observed in other contexts (Tu and Johnson, 2010; Singh et al., 2014; Spiewak et al., 2018). Such cells occurred on the body and fin, and in these presumptive clones, erythrophores and xanthophores were almost always co-labeled (Figure 3B), consistent with a common progenitor for erythrophores and xanthophores.

A common progenitor could be specified for erythrophore or xanthophore fates either before or after colonizing the fin. To distinguish between these possibilities we used aox 5 reporter expression as an indicator of specification and a nuclear localizing photoconvertible (green $\rightarrow$ red) fluorophore, nucEosFP, to determine whether cells already expressing this marker transit from body to fin. We generated a transgenic line, $\mathrm{Tg}$ (aox5:nucEosFP) vp37albTg, which allowed us to photoconvert all aox5:nucEosFP+ cells on the body prior to anal fin development (6.5 $\mathrm{mm} \mathrm{SL}$ ). We then assessed the distribution of converted and unconverted nucEosFP $4 \mathrm{~d}$ later, when the anal fin had started to form $(7.5 \mathrm{~mm} \mathrm{SL})$. Because aox5 expression persists once initiated, cells photoconverted at one stage will later have converted fluorophore, (displayed in magenta), as well as new, unconverted fluorophore (green), so nuclei will appear white; cells that initiate aox5 expression only after photoconversion will have only unconverted fluorophore and nuclei that are green.

We found that cells on the body had converted and unconverted fluorophore, whereas cells in the fin had only unconverted fluorophore, consistent with initiation of aox 5 expression only after progenitors had colonized the fin (Figure $3 C$ ). Because it remained possible that some cells had migrated from body to fin and proliferated so extensively that signal of converted nucEosFP was lost by dilution, we repeated these analyses but assessed distributions of cells 1 $\mathrm{d}$ after photoconversion; we then photoconverted (or reconverted) all cells on body and fin and repeated this process on successive days. Such labeling failed to reveal cells that translocated from body to fin, though it did reveal numerous cells that acquired aox 5 expression when already in the fin (Figure 3D). Together these observations suggest that progenitors migrate to the fin, become specified for erythrophore or xanthophore lineages within the fin, and then 
contribute to both populations as they proliferate to populate the proximal-distal axis during fin outgrowth.

\section{Erythrophores and xanthophores arise from fate-restricted and unrestricted precursors in the fin and their fates remain plastic even after differentiation}

Clones identified by scarb1 activity or aox5 transgene expression (Figure $\mathbf{3 A , B}$ ) likely represented progenitors segregated from other lineages during early development when injected Cas9 is active and transgene integration occurs [e.g., (Tryon et al., 2011)]; these clones presumably also included melanophores or other cell types not revealed by these markers (Tu and Johnson, 2010; Tu and Johnson, 2011; Lewis et al., 2019). We therefore asked whether progeny of such clones that had already colonized the fin were restricted to either erythrophore or xanthophore fates by photoconverting individual nucEosFP+ cells at early stages of fin development (7.0-8.5 mm SL) and then assessing phenotypes of resulting clones around 30-36 d later (15.0 mm SL). At $7.0 \mathrm{~mm} \mathrm{SL}$, only unpigmented nucEosFP+ cells were present (Figure $\mathbf{4 A}$, top). Preliminary observations indicated that proximally located cells tended to remain in the proximal region where erythrophores develop, so we photoconverted cells in distal regions that might become more broadly distributed. Resulting clones consisted of erythrophores if daughter cells remained relatively proximal as the fin grew out, or both erythrophores and xanthophores if daughter cells became distributed across the proximodistal axis (Figure 4B,C, Figure 4-figure supplement 1A). At $7.5 \mathrm{~mm}$, many nucEosFP+ cells had acquired a pale orange color (Figure $\mathbf{4 A}$, bottom) and so we asked whether these cells had become fate-restricted with the onset of pigmentation. Similar to unpigmented cells, however, initially proximal orange cells generated only erythrophores, whereas initially distal orange cells could generate clones of only erythrophores, both erythrophores and xanthophores, or only xanthophores, depending on where daughter cells were distributed (Figure 4C, Figure 4-figure supplement 1B). Finally, at $8.5 \mathrm{~mm}$ we found that still-unpigmented nucEosFP+ cells near the distal fin tip generated distal clones restricted to a xanthophore fate (Figure 4-figure supplement 1C). These results show that individual unpigmented cells and early-developing orange cells in the fin can generate both erythrophores and xanthophores, depending on initial location and where progeny localize.

We further asked whether phenotypes of erythrophores and xanthophores might be plastic even after they differentiate by challenging cells in a regenerative context. To test for erythrophore $\rightarrow$ xanthophore conversion, we amputated fins through the region containing erythrophores, expecting that regeneration distally might allow for repositioning of erythrophores into regions where regenerative xanthophores would be expected, with conditions favorable to fate conversion, should cells retain such potential. In brightfield images, erythrophores appeared to divide, and to gradually change from red to yellow (Figure 5A). To confirm these observations, we marked nucEosFP+ erythrophores by photoconversion prior to amputation (Figure 5B; Figure 5-figure supplement 1A). Many erythrophores divided to replenish their complement in proximally regenerating tissue, and a few erythrophores differentiated from unpigmented precursors, as indicated by the presence, or absence of photoconverted nucEosFP, respectively (Figure 5-figure supplement 1B). Additionally, some initially marked erythrophores came to occupy more distal regions and were indistinguishable from regenerative xanthophores that had developed from unpigmented progenitors even 36-51 days postamputation (Figure 5C). These findings suggest a reduction in pre-existing red pigment as cells divide, and a failure to accumulate new red pigments once proliferation has ceased. We also sought to determine whether xanthophores can transition to an erythrophore fate by ablating central regions of fin and then assessing whether distal xanthophores can move into the 
regenerating proximal region. However, these experiments were not informative, as regenerative tissue was colonized by erythrophores or xanthophores differentiated from progenitors rather than pre-existing xanthophores (Figure 5-figure supplement 2).

These observations indicate that erythrophores and xanthophores of the adult anal fin share a lineage, that individual progenitor cells within the fin can contribute to both cell types, and that some plasticity in fate persists even after differentiation, with erythrophores able to transition to a yellow-pigmented phenotype when challenged to do so.

\section{Genetic requirements and biochemical basis for red coloration}

To better understand molecular mechanisms of red coloration we compared gene expression between fin regions containing only erythrophores or only xanthophores. Erythrophores occurred at only one-third the density of xanthophores in two dimensional images (Figure 2figure supplement $1 D$ and see below) and proximal and distal fin regions presumably differ in ways other than chromatophore content. Nevertheless, we reasoned that comparisons of bulk tissue preparations might still identify genes having marked differences in expression between erythrophores and xanthophores, as would be expected for loci functioning in pigment synthesis (Saunders et al., 2019). Mapping $D$. albolineatus sequencing reads to the zebrafish genome identified 18,050 expressed genes. Transcripts of 162 genes were more abundant in proximal erythrophore-containing tissue, whereas 200 genes were more abundant in distal xanthophorecontaining tissue ( $q<0.05$; fold-changes $=0.4-6.8$ ) (Figure 6A and 6B; Supplementary File 1-Table 1).

To identify genes required for red or yellow coloration, we used CRISPR/Cas9 mutagenesis to knock out selected candidates that might have roles in processing of carotenoids, synthesis of other pigments, or fate specification (Supplementary File 1-Tables 2 and 3). We screened mosaic (F0) fish and isolated stable lines of mutant alleles for target genes with pigmentary phenotypes. Of 25 targets derived from RNA-seq, three yielded mutants with defects in pigmentation. To determine which pigments contributed to colors present in wild-type, and which were affected in mutants, we further assayed the carotenoid content of fin regions by HPLC.

In the wild type, fin tissue containing erythrophores was markedly enriched for the red ketocarotenoid astaxanthin; additional peaks had profiles consistent with other ketocarotenoids (Figure 7A, peak 3; Figure 7-figure supplement 1; Supplementary File 1-Table 4). Fin tissue containing xanthophores lacked astaxanthin and instead contained yellow zeaxanthin (peak 10), similar to zebrafish xanthophores (Saunders et al., 2019), as well as additional peaks characteristic of other yellow xanthophyll carotenoids.

To confirm that carotenoids rather than other pigments are principally responsible for pigmentation, we recovered mutant alleles of scarb1, required for carotenoid uptake and localization (Toomey et al., 2017; Saunders et al., 2019), as residual color in such mutants would suggest a non-carotenoid contribution. We isolated two alleles, scarb1 vp38ac1 $^{\text {(V84 }}$ 16X) and scarb 1vp38ac2 (V84X), and found that scarb1 1v38ac1/vp38ac2 individuals had a phenotype concordant with that of F0 mosaics (Figure $3 A$ ): they lacked color in the visible range and lacked carotenoids detectable by HPLC (Figure 7B; Figure 7-figure supplement 2A; Supplementary File 1-Table 4). The absence of residual red or yellow coloration suggested that pteridine pigments do not contribute to visible color in these cells, as they do in some other species (Goodrich et al., 1941; Matsumoto, 1965; Grether et al., 2001; Weiss et al., 2012; Olsson et al., 2013). Moreover, targeting of differentially expressed genes known to function in 
pteridine synthesis did not yield visible pigmentation defects in F0 mosaics (erythrophore region: spra, xdh; xanthophore region: aox5; Supplementary File 1-Tables 1 and 4). Pteridine pigments were detectable histologically in erythrophores and xanthophores, however, and could be visible in the UV range (Figure 7-figure supplement $2 B$ ).

Mutants for two genes, cyp2ae2 (FO904880.1) and bdh1a (zgc:113142), lacked overt red coloration (Figure 7C, Figure 7-figure supplement 2A), though densities of erythrophores and xanthophores did not differ significantly from wild-type (Figure 7F). Both genes had transcripts that were more abundant in fin tissue containing erythrophores than xanthophores ( $\log _{2}$ fold-changes $=4.9,2.1 ; q=9.6 \mathrm{E}-23,8.9 \mathrm{E}-8$; Figure 6). We confirmed by RT-PCR that both genes were expressed in erythrophores picked manually by micropipette from dissociated fin tissue (Figure 7-figure supplement 3A).

cyp2ae2 encodes an enzyme within the large family of cytochrome P450 monooxygenases (Kirischian et al., 2011). A related gene encoding a different P450 family member, CYP2J19, is essential for red coloration in "red factor" canary (Lopes et al., 2016) and zebra finch (Mundy et al., 2016), and likely has similar roles in other birds and turtles (Twyman et al., 2016; Twyman et al., 2018). CYP2J19 expression is testosterone-dependent (Khalil et al., 2020) and its product is believed to mediate the conversion of yellow carotenoids like zeaxanthin into red ketocarotenoids like astaxanthin (Figure 1A). Orthologs of CYP2J19 appear to be restricted to birds and turtles (Twyman et al., 2016). Reciprocally, cyp2ae2 (FO904880.1) is clearly a member of the cyp2 family, and is likely orthologous to cyp2ae1 loci of other teleosts by sequence similarity and chromosomal position, yet no clear orthologues of this gene are present in amniotes (Ensembl Release 103) (Kirischian et al., 2011; Yates et al., 2020). The loss of red color in $D$. albolineatus erythrophores thus raises the possibility that CYP2J19 and Cyp2ae2 may have acquired carotenoid ketolase activity convergently. Supporting the idea that cyp2ae2 might encode a carotenoid ketolase, the cyp2ae2 mutant had markedly reduced amounts of astaxanthin in fin regions containing erythrophores but relatively greater amounts of zeaxanthin (peak 10) in both erythrophore and xanthophore containing tissue as compared to wild-type, consistent with cyp2ae2 expression in both tissues, albeit at different levels (Figure $7 C$ Supplementary File 2-Table 5). Consistent with these findings, erythrophores of cyp2ae2 mutants had markedly reduced red/green fluorescence ratios (Figure $7 D$ ) and a reduced diameter of visible pigment (Figure $7 E$ ). Trace residual astanxanthin and other ketocarotenoids are unlikely to reflect residual activity of cyp2ae2, as the mutant allele, cyp2ae2vp39ac1, harbors a 5-nucleotide frameshift within the first coding exon leading to 42 novel amino acids followed by a premature stop codon (L46 $\Delta 43 \mathrm{X}$ ). A paralogous locus, cyp2ae1, lies adjacent to cyp2ae2 and was expressed at very low levels in both fin regions (Figure 7-figure supplement 3B;

Supplementary File 1-Table 1). Compensatory activity of cyp2ae1 might account for trace levels of ketocarotenoids in cyp2ae2 ${ }^{\text {vp39ac1. }}$

The second red-deficient mutant, bdh1a, encodes 3-hydroxybutyrate dehydrogenase type 1a, a short-chain dehydrogenase/reductase that in mammals is known to interconvert hydroxyl and ketone groups, and in particular acetoacetate and 3-hydroxybutyrate, two major ketone bodies (Green et al., 1996; Langston et al., 1996; Persson et al., 2009; Otsuka et al., 2020). Though not implicated previously in carotenoid processing or red coloration, transcripts of a homologous gene were enriched in orange skin of clownfish Amphiprion ocellaris (Salis et al., 2019). The bdh1a vp40ac1 mutant (D141 $12 \mathrm{X}$ ) completely lacked astaxanthin and other ketocarotenoids in erythrophore-containing tissue, and did not exhibit increased levels of zeaxanthin, as observed in cyp2ae2 ${ }^{\text {vpa39c1 }}$ (Figure 7C). Red/green fluorescence ratios of erythrophores are similar to those of xanthophores (Figure $7 D$ ) and the diameter of visible 
pigment is reduced from wild-type levels in erythrophores though not xanthophores (Figure 7E), confirming the visible phenotype.

Erythrophores of cyp2ae2 and bdh1a mutant fish appeared normal in size and shape in young adults yet became morphologically heterogeneous as fish age, with pigment-containing cell fragments and fewer cells evident, as well as an onset of whole-fish kyphosis, by $\sim 12$ months post-fertilization (Figure 7-figure supplement 3C). These phenotypes suggest requirements for both loci in the accumulation of red carotenoids and subsequent homeostasis of erythrophores and other tissues, perhaps associated with a systemic dysregulation of carotenoid-Vitamin A-retinoid metabolism (von Lintig et al., 2005; Ghyselinck and Duester, 2019).

$\beta$-carotene oxygenase 1 (Bco1) symmetrically cleaves $\beta$-carotene to produce vitamin $A$, a precursor of retinoic acid; whereas $\beta$-carotene oxygenase 2 (Bco2) cleaves a variety of carotenoids in an asymmetric fashion, leading to their degradation (Li et al., 2017; Harrison and Kopec, 2020; Poliakov et al., 2020) (Widjaja-Adhi et al., 2015). bco1 and bco2b were more abundant in tissue containing xanthophores than erythrophores $\left(\log _{2} \mathrm{FC}=4.9,2.1 ; q=9.6 \mathrm{E}-23\right.$, 8.9E-8); a third locus, bco2/ was similarly abundant at both sites (Supplementary File 1-Table 1). Given heterogeneities in transcript abundance, we asked whether $\beta$-carotene oxygenase genes might also contribute to differences in carotenoid accumulation between cell types. Only bco1-targeted fish exhibited an overt pigmentary phenotype in F0 mosaic animals, with pigmentfree patches alongside patches of cells having apparently normal pigmentation consistent with a pigment-cell autonomous function (Figure 7-figure supplement 2C). Mutants stably carrying bco1 alleles (bco1vp41ac1, 52D $\Delta 5 \mathrm{X}$; bco 1vp41ac2, 51F $\Delta 9 \mathrm{X}$ ) had reduced carotenoid levels in both xanthophores and erythrophores as well as smaller diameters of contracted pigment granules (Figure 7C-E; Figure 7-figure supplement 2A and 2B). The mechanism of this effect on chromatophore carotenoid content remains unclear.

\section{Discussion}

Red and orange coloration play important roles in multiple behaviors, including mate choice (see Introduction). As a first step towards understanding the development of such colors and the mechanisms underlying their phylogenetic distribution in the zebrafish genus Danio, we investigated the cell lineage origins and genetic requirements for erythrophore differentiation in $D$. albolineatus. These analyses provide new insights into the diversification of adult pigment cell types in teleosts and identify genes contributing to the red ketocarotenoid coloration in this species and possibly more distant taxa as well.

Fate mapping and clonal analyses indicated that at least some erythrophores and xanthophores share a common progenitor in the fin. Clones of cells marked genetically during early development later contained both cell types, indicating a shared progenitor that likely colonizes the fin during its initial outgrowth, consistent with inferences for melanophore and xanthophore progenitors of zebrafish fins (Tu and Johnson, 2010; Tu and Johnson, 2011). In D. albolineatus, these progenitors appear to become specified for erythrophore or xanthophore fates-as inferred from aox 5 transgene expression-only after colonizing the fin. We did not observe pigmented cells transit from the body to the fin, though such cells could be found at the base of the fin without entering the fin itself. These findings might appear to differ from that of a prior study, in which erythrophores on the body were described as invading the fin (Goodrich and Greene, 1959). Yet those observations were made with the caveat that an appearance of 
invasion could also reflect de novo differentiation within regions not previously occupied by these cells, rather than active migration per se. We conclude that unpigmented progenitors enter the fin and only then become specified to erythrophore or xanthophores fates.

At early stages of fin outgrowth, some initially unpigmented progenitors acquire an orange color, intermediate between that of fully differentiated erythrophores and xanthophores. When these early orange cells were marked individually by photoconversion of a transgenic reporter, some cells initially at middle positions along the fin proximodistal axis gave rise to both erythrophores and xanthophores, whereas other more proximal or more distal cells contributed to only erythrophore or xanthophores, respectively. These observations indicate a bipotentiality, with fate(s) choice presumably dependent on factors in the fin environment. Our finding that erythrophores can lose their red color when joining a regenerative population of xanthophores further indicates a subsequent plasticity in these fates. At later stages of fin development, unpigmented cells developed directly as xanthophores in distal regions. Whether these represent a distinct sublineage remains to be determined.

Red and orange colors can be generated in various ways. In mammals, reddish hues typically depend on the production of phaeomelanin by melanocytes, which is transferred to keratinocytes for incorporation into hair (Hubbard et al., 2010; Caro and Mallarino, 2020). In birds, phaeomelanin is also known to contribute to brownish-red feather coloration (McGraw et al., 2005; Cruz-Miralles et al., 2020), but more vibrant reds and oranges typically depend on carotenoids, accumulated, processed, and eventually deposited in developing feathers (Lopes et al., 2016; Mundy et al., 2016; Toews et al., 2017). In lizards, reds are most often the result of pteridine pigments (Olsson et al., 2013), contained within xanthophores, whereas in amphibians and teleosts these colors can result from with pteridines as well as carotenoids in xanthophores and erythrophores (Matsumoto, 1965; Wedekind et al., 1998; Grether et al., 2001; Bagnara and Matsumoto, 2006; Sefc et al., 2014). Our analyses show that in D. albolineatus, red and orange colors of adult erythrophores and xanthophores result from carotenoids, detectable by HPLC and lost in scarb1 mutants. Though pteridines were detectable histologically in erythrophores these did not affect color in the visible range. These observations are concordant with findings from zebrafish, in which the yellow-orange color of xanthophores in adults depends on carotenoids (Saunders et al., 2019), whereas yellow coloration of the same cells in embryos and early larvae depends on pteridines (Ziegler, 2003; Lister, 2019).

The precise biochemical mechanism whereby yellow carotenoids (e.g., zeaxanthin) are converted into ketocarotenoids in animals remains incompletely understood (Strange, 2016; Toews et al., 2017). In birds, an essential role has been demonstrated for CYP2J19, which is thought to mediate the C4-ketolation of carotenoids (Lopes et al., 2016; Mundy et al., 2016). Our analyses show that another member of the cyp2 P450 subfamily, cyp2ae2, is required for ketocarotenoid accumulation in erythrophores. The finding that two different members of the cyp2 subfamily may have converged on a role in ketocarotenoid formation, suggests that this subgroup of P450 enzymes may be uniquely poised to evolve ketolase activity. Nevertheless, the biochemical function of these enzymes has yet to be demonstrated in vitro, and full ketolase activity may depend on additional factors. In this regard, the markedly reduced abundance of red carotenoids in bdh1a mutant erythrophores may provide further clues to the biochemical mechanism of ketocarotenoid production. Indeed, our finding that bco1 mutants have reduced levels of both red and yellow carotenoids - contrary to the expected activity of this enzyme in carotenoid degradation (Harrison and Kopec, 2020) and observations in other systemssuggests biochemical functions and compensatory interactions in this system worthy of further exploration. 
The diversification of pigment patterns in teleost has been accompanied by a diversification of pigment cell types, with several distinct classes of iridophores, xanthophores, and leucophores now recognized in Danio fishes alone (Oshima and Kasai, 2002; Hirata et al., 2003; Lewis et al., 2019; Saunders et al., 2019; Gur et al., 2020). Additional subtypes of pigment cells and even mosaic pigment cells with properties of more than one type have been recognized in more distant teleosts (Ballowitz, 1913; Goodrich et al., 1941; Asada, 1978; Goda and Fujii, 1995; Goda et al., 2011; Goda et al., 2013; Djurdjevič et al., 2015; Salis et al., 2019; Parichy, 2021). In at least one instance cells of one type can transition directly into another type (melanophores $\rightarrow$ melanoleucophores) (Lewis et al., 2019), whereas in another instance subtypes derived from a common progenitor (stripe and interstripe iridophores) are refractory to interconversion even when challenged to do so experimentally (Gur et al., 2020). Our observations of erythrophore and xanthophore origins and fate plasticity suggest a relatively subtle distinction, perhaps limited to the activation or repression of genes essential for the color difference itself. The particular mechanisms that specify these fates or deployment of particular biochemical pathways, and whether additional phenotypes distinguish these cells remain to be elucidated. Such efforts in $D$. albolineatus, and corresponding investigations to uncover genetic bases of erythrophore loss in zebrafish, will be enabled by the identification of cell-type specific pigments and the development of methods to quantify pigmentary phenotypes in live animals.

\section{Materials and methods}

\section{Key Resources Table}

\begin{tabular}{|c|c|c|c|c|}
\hline $\begin{array}{l}\text { Reagent type } \\
\text { (species or resource)* }^{*}\end{array}$ & Designation & Source or reference & Identifiers & $\begin{array}{l}\text { Additional } \\
\text { information }\end{array}$ \\
\hline Species, D. albolineatus & wild-type & this paper & NA & NA \\
\hline Species, $D$. albolineatus & $\operatorname{Tg}(a o x 5: n u c E o s)$ vp37albTg & this paper & NA & NA \\
\hline Species, D. albolineatus & scarb1vp38ac1 & this paper & NA & NA \\
\hline Species, $D$. albolineatus & scarb1vp38ac2 & this paper & NA & NA \\
\hline Species, $D$. albolineatus & сур2ае2vр39ас1 & this paper & NA & NA \\
\hline Species, D. albolineatus & bdh1avp40ac1 & this paper & NA & NA \\
\hline Species, $D$. albolineatus & bco1vp41ac1 & this paper & NA & NA \\
\hline Species, $D$. albolineatus & bco1vp41ac2 & this paper & NA & NA \\
\hline Recombinant DNA reagent & mitfa:nucEosFP & this paper & NA & NA \\
\hline Recombinant DNA reagent & aox5:palmEGFP & McMenamin et al. 2014 & NA & NA \\
\hline Software, algorithm & JMP Pro 16 & SAS Institute & NA & NA \\
\hline Software, algorithm & GraphPad Prism & GraphPad & NA & NA \\
\hline Software, algorithm & Fiji & Schindelin et al. 2012 & NA & NA \\
\hline Software, algorithm & Kallisto & Bray et al. 2016 & NA & NA \\
\hline Software, algorithm & DESeq2 & Love et al. 2014 & NA & NA \\
\hline
\end{tabular}

* additional oligonucleotides and CRIPSR/Cas9 reagents provided in Supplementary File 1-Tables 2 and 5

\section{Ethics statement}

All animal research was conducted according to federal, state and institutional guidelines and in accordance with protocols approved by Institutional Animal Care and Use Committees at University of Washington and University of Virginia. Euthanasia was performed by MS-222 overdose followed by physical maceration in compliance with institutional and AVMA guidelines. 


\section{Fish stocks and rearing conditions}

Danio albolineatus were derived from individuals collected in Thailand by M. McClure in 1995 (McClure et al., 2006), provided to the laboratory of S. Johnson, and then maintained in our laboratory from 2000 until the present. Additional species of Danio used for assessing erythrophore complements were obtained directly from the field or through the pet trade $[D$. aesculapii; D. quagga, D. kyathit (McCluskey et al., 2021); D. nigrofasciatus, D. tinwini (Spiewak et al., 2018); D. kerri; D. choprae; D. margaritatus, D. eythromicron] and maintained subsequently in the lab or were observed in the field $[D$. meghalayensis, $D$. dangila (Engeszer et al., 2007)]. Fish were reared under standard conditions to maintain $D$. rerio $\left(\sim 28^{\circ} \mathrm{C} ; 14 \mathrm{~L}: 10 \mathrm{D}\right)$ with larvae fed initially marine rotifers, derived from high-density cultures and enriched with Rotimac and Algamac (Reed Mariculture), with older larvae and adults subsequently fed live brine shrimp and a blend of flake foods enriched with dried spirulina. Stocks of mutant or

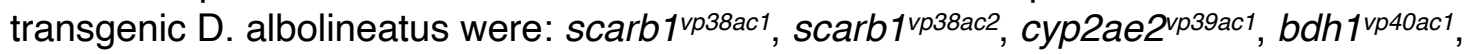
bdh1vp40ac2, csf1ravp4ac1, Tg(aox5:nucEosFP) vp43aTg.

\section{CRISPR/Cas9 mutagenesis}

Mutants were generated by injecting one-cell stage embryos with $200 \mathrm{ng} / \mathrm{ml}$ sgRNAs and 500 $\mathrm{ng} / \mathrm{ml}$ Cas9 protein (PNA Bio) using standard procedures (Shah et al., 2015) as well as (Alt-R S.p. Cas9 nuclease, v.3) and Alt-R CRISPR-Cas9 sgRNAs synthesized by Integrated DNA Technologies (IDT). F0 fish were sorted for anal fin phenotypes at juvenile stages and alleles recovered by intercrossing and outcrossing.

\section{Transgenesis}

aox5:nucEosFP and mitfa:nucEosFP plasmids were made by assembling $8 \mathrm{~kb}$ aox 5 and $5 \mathrm{~kb}$ mitfa promoters with nuclear-localizing photoconvertible fluorophore EosFP using the tol2 Gateway Kit (Kwan et al., 2007), and were injected together with tol2 mRNA into one-cell stage embryos (Suster et al., 2009).

\section{Imaging}

Whole fish were euthanized then embedded in $1 \%$ low-melt agarose, and captured on a Nikon D-810 digital single lens reflex camera with MicroNikkor $105 \mathrm{~mm}$ macro lens. Anal fin details were imaged using a Zeiss Axio Observer inverted microscope or Zeiss AxioZoom stereomicroscope equipped with Zeiss Axiocam cameras.

Carotenoid autofluorescence was imaged using a Zeiss LSM880 inverted laser confocal microscope in Airyscan SR mode. Laser intensity for red (excitation wavelength $561 \mathrm{~nm}$ ) and green (excitation wavelength $488 \mathrm{~nm}$ ) channels were set to be identical. For comparison with brightfield illumination, anal fins were stabilized with a few drops of $1 \%$ low-melt agarose then specimens transferred to a Zeiss AxioObserver inverted microscope with Axiocam camera. Cells along the mid line of $10^{\text {th }}$ inter-fin ray were imaged. Background of bright field images was corrected to white using software Fiji imageJ (Schindelin et al., 2012): Duplicate> Gaussian Blur $=50>$ Image Calculator to subtract background $>$ Invert. For larva to juvenile comparisons (Figure $1 F$ ), 10 cells in $3^{\text {rd }}$ and $4^{\text {th }}$ inter-fin ray in proximal and distal were imaged. For wild-type and mutant comparisons (Figure $7 D$ ), 20 cells in 10 $10^{\text {th }}$ inter-fin ray in proximal and distal were imaged. Other fluorescent images (e.g., photoconverted images, aox5+ clonal labeling) were acquired using a Zeiss AxioObserver inverted microscope equipped with Yokogawa CSUX1M5000 laser spinning disk and Hamatsu camera. 


\section{Fate mapping and lineage analysis}

Photoconversion was performed on $\mathrm{Tg}($ aox5:nucEosFP) or plasmid-injected F0 mitfa:nucEosFP, using a Zeiss LSM 800 scanning laser confocal with a $405 \mathrm{~nm}$ laser and ZEN blue software. Fish were subsequently reared in tanks shaded from ambient light to prevent spontaneous photoconversion (McMenamin et al., 2014; Gur et al., 2020). Brightfield images were taken before photoconversion and fish inspected to ensure that no photoconversion had occurred as a result. Subsequent imaging used fluorescence channels only, except for endpoint imaging in fluorescence followed by brightfield. Although pigments autofluoresce in the same channels as nucEosFP, treatment with epinephrine allowed contracted pigment granules to be distinguished unambiguously from nuclei.

For amputation experiments, fins were transected through the middle of the erythrophorecontaining region, and imaged subsequently in brightfield (Figure $5 A$ ) following treatment with epinephrine. Alternatively, $\mathrm{Tg}($ aox5:nucEosFP) adult males were exposed under an external Zeiss HXP $120 \mathrm{~V}$ compact light source for 15 min until all nucEosFP+ cells in fins had been converted (Figure 5C). Fish were anesthetized and anal fins amputated through erythrophore regions, then reared in a shaded tank as above. Unconverted controls reared in the same tank did not show any converted nucEosFP signal when examined concurrently at subsequent time points. Sham control (photoconverted without amputation) of regeneration experiment in Figure $5 \mathrm{C}$. Converted nucEosFP signal remained very strong after 41 days. Images were taken one day after amputation and at the end point of the experiment. For excisions of middle fin regions (Figure 5-figure supplement 2), internal fin ray and inter-fin ray regions were removed and xanthophores close to the wound photoconverted.

\section{Reverse transcription polymerase chain reaction (RT-PCR) analysis}

Adult male anal fins were dissected and dissociated enzymatically dissociated with Liberase (Sigma-Aldrich cat. $5401119001,0.25 \mathrm{mg} / \mathrm{mL}$ in dPBS) at $25^{\circ} \mathrm{C}$ for $15 \mathrm{~min}$ followed by gently pipetting for $5 \mathrm{~min}$. Cell suspensions were then filtered through a 70 um Nylon cell strainer to obtain a single cell suspension. Individual cells were then picked manually under Zeiss Axio Observer inverted microscope. Cells were identified by their morphology: red erythrophores, yellow xanthophores, black melanophores and transparent small skin cells. Total RNAs were isolated by RNeasy Protect Mini Kit (Qiagen) and cDNAs synthesized with oligo-dT priming using SuperScript III Cells Direct cDNA Synthesis System (Thermo). Primers pairs were designed to span exon-intron junctions or long introns for assessing genomic contamination, targeting (Supplementary File 1-Table 5). Amplifications were performed using Taq polymerase with 35 cycles of $95^{\circ} \mathrm{C}$ for $30 \mathrm{~s}, 56^{\circ} \mathrm{C}$ for $30 \mathrm{~s}, 72^{\circ} \mathrm{C}$ for $15 \mathrm{~s}$.

\section{Pteridine Autofluorescence}

To assess pteridine content, amputated fins were imaged after exposure to dilute ammonia $(\mathrm{pH}$ 10.0), which liberates pteridines from protein carriers resulting in autofluorescence under DAPI illumination.

\section{RNA-seq}

Adult male Danio albolineatus were euthanized, anal fins were dissected and tissue collected from proximal erythrophore or distal xanthophore regions in PBS. RNA was extracted using TRIzol and Direct-zol RNA MiniPrep Kit. mRNA was enriched using NEBNext Poly(A) mRNA Magnetic Isolation Module and sequencing libraries were constructed using NEBNext Ultra RNA 
Library Prep Kit for Illumina and sequenced on an Illumina Nextseq-500. Reads were aligned to Danio rerio reference genome GRCz11 using Kallisto (Bray et al., 2016) and analyzed using DESeq2 (Love et al., 2014) (Love et al., 2014).

\section{Carotenoid analyses}

Proximal (erythrophore containing) and distal (xanthophore containing) portions of the anal fin were dissected from nine individuals of each genotype and like samples were combined in pools of three for pigment extraction. The pooled fin tissue was homogenized with zirconia beads in $1.2 \mathrm{ml}$ of $0.9 \%$ sodium chloride and protein content was quantified a bicinchoninic acid (BCA) assay (23250, Thermo). Carotenoids were extracted from the homogenates by combining $1 \mathrm{ml}$ methanol, $2 \mathrm{ml}$ distilled water, and $2 \mathrm{ml}$ of hexane:tert-methyl butyl ether (1:1 vol:vol), collecting and drying the resulting solvent fraction under nitrogen. Each sample was then split and saponified with $0.02 \mathrm{M} \mathrm{NaOH}$ or $0.2 \mathrm{M} \mathrm{NaOH}$ in methanol at room temperature to maximize the recovery of ketocarotenoids or other xanthophylls, respectively (Toomey and McGraw, 2007). The saponified extracts were then injected into an Agilent 1100 series HPLC fitted with a YMC carotenoid $5.0 \mu \mathrm{m}$ column $(4.6 \mathrm{~mm} \times 250 \mathrm{~mm}, \mathrm{YMC})$. Carotenoids were separated with a gradient mobile phase of acetonitrile:methanol:dichloromethane (44:44:12) (vol:vol:vol) through 11 minutes, a ramp up to solvent ratios of 35:35:30 for 11-21 minutes and isocratic conditions through 35 minutes. The column was maintained at $30^{\circ} \mathrm{C}$ with a mobile phase flow rate of $1.2 \mathrm{ml}$ $\mathrm{min}^{-1}$ throughout. The samples were monitored with a photodiode array detector at 400, 445, and $480 \mathrm{~nm}$, and carotenoids were identified and quantified by comparison to authentic standards (a gift of DSM Nutritional Products, Heerlen, The Netherlands).

\section{Statistical Analyses}

Analyses of quantitative data were performed in JMP Pro 16 (SAS Institute, Cary NC).

\section{Acknowledgements}

Supported by NIH R35 GM122471 to DMP and startup funds from the University of Tulsa to MBT. Thanks to Jin Liu for assistance with screening, stock propagation and imaging, Lauren Saunders and Andy Aman for assistance with RNA-Seq, Amber Schwindling for fish husbandry, and Tarah Foster for assistance with carotenoid analyses. 


\section{References}

Asada M. 1978. Presence of melanosome-like granules in dermal erythrophores of tropical teleost (Badis badis). Experientia 34:511-2. doi: 10.1007/bf01935961, PMID: WOS:A1978EV37700065

Bagnara JT, Matsumoto J. Chapter 2. Comparative anatomy and physiology of pigment cells in nonmammalian tissues. In: Nordland JJ, Boissy RE, Hearing VJ, King RA, Oetting WS, Ortonne JP, editors. The Pigmentary System: Physiology and Pathophysiology. New York, New York: Oxford University Press; 2006.

Ballowitz E. 1913. Über schwarz-rote und sternformig Farbzellenkombinationen in der Haut von Gobiiden. Ein weiterer Beitrag zur Kenntnis der Chromatophore und ChromatophorenVereinigungen Knochenfischen. Zeitschrift für Wissenschaftliche Zoologie 106:527-93.

Bray NL, Pimentel H, Melsted P, Pachter L. 2016. Near-optimal probabilistic RNA-seq quantification. Nat Biotechno/ 34:525-7. doi: 10.1038/nbt.3519, PMID: 27043002

Brodie ED, Brodie ED. 1980. Differential Avoidance of Mimetic Salamanders by Free-Ranging Birds. Science 208:181. doi: 10.1126/science.208.4440.181,

Budi EH, Patterson LB, Parichy DM. 2011. Post-embryonic nerve-associated precursors to adult pigment cells: genetic requirements and dynamics of morphogenesis and differentiation. PLOS Genet 7:e1002044. doi: 10.1371/journal.pgen.1002044, PMID: 21625562

Caro T, Mallarino R. 2020. Coloration in Mammals. Trends Ecol Evol 35:357-66. doi: 10.1016/j.tree.2019.12.008, PMID: 31980234

Cruz-Miralles A, Aviles JM, Chastel O, Exposito-Granados M, Parejo D. 2020. Phaeomelanin matters: Redness associates with inter-individual differences in behaviour and feather corticosterone in male scops owls (Otus scops). PLoS One 15:e0241380. doi: 10.1371/journal.pone.0241380, PMID: 33175892

Dijkstra PD, Hemelrijk C, Seehausen O, Groothuis TGG. 2009. Color polymorphism and intrasexual competition in assemblages of cichlid fish. Behavioral Ecology 20:138-44. doi: 10.1093/beheco/arn125,

Djurdjevic I, Kreft ME, Bajec SS. 2015. Comparison of pigment cell ultrastructure and organisation in the dermis of marble trout and brown trout, and first description of erythrophore ultrastructure in salmonids. Journal of Anatomy 227:583-95. doi: 10.1111/joa.12373, PMID: WOS:000363210100001

Djurdjevič I, Kreft ME, Sušnik Bajec S. 2015. Comparison of pigment cell ultrastructure and organisation in the dermis of marble trout and brown trout, and first description of erythrophore ultrastructure in salmonids. Journal of Anatomy:n/a-n/a. doi: 10.1111/joa.12373,

Dooley CM, Mongera A, Walderich B, Nusslein-Volhard C. 2013. On the embryonic origin of adult melanophores: the role of ErbB and Kit signalling in establishing melanophore stem cells in zebrafish. Development 140:1003-13. doi: 10.1242/dev.087007, PMID: 23364329

Endler JA. 1980. Natural-Selection on color patterns in Poecilia reticulata. Evolution 34:76-91. doi: Doi 10.2307/2408316, PMID: WOS:A1980JL58600006

Engeszer RE, Patterson LB, Rao AA, Parichy DM. 2007. Zebrafish in the wild: a review of natural history and new notes from the field. Zebrafish 4:21-40. doi: 10.1089/zeb.2006.9997, PMID: 18041940

Eriksson J, Larson G, Gunnarsson U, Bed'hom B, Tixier-Boichard M, Stromstedt L, Wright D, Jungerius A, Vereijken A, Randi E, Jensen P, Andersson L. 2008. Identification of the yellow skin 
gene reveals a hybrid origin of the domestic chicken. PLoS Genet 4:e1000010. doi: 10.1371/journal.pgen.1000010, PMID: 18454198

Evans MR, Norris K. 1996. The importance of carotenoids in signaling during aggressive interactions between male firemouth cichlids (Cichlasoma meeki). Behavioral Ecology 7:1-6. doi: 10.1093/beheco/7.1.1, PMID: WOS:A1996UF66900001

Fang F, Kottelat M. 2000. Danio roseus, a new species from the Mekong basin in northeastern Thailand and northwestern Laos (Teleostei: Cyprinidae). Ichthyol Explor Freshwaters 11:149-54.

Ghyselinck NB, Duester G. 2019. Retinoic acid signaling pathways. Development 146. doi: 10.1242/dev.167502, PMID: 31273085

Goda M, Fujii R. 1995. Blue chromatophores in two species of callionymid fish. Zoological Science 12:811-3. doi: Doi 10.2108/Zsj.12.811, PMID: WOS:A1995TT47500019

Goda M, Fujiyoshi Y, Sugimoto M, Fujii R. 2013. Novel Dichromatic Chromatophores in the Integument of the Mandarin Fish Synchiropus splendidus. Biol Bull-Us 224:14-7. PMID: WOS:000317802800002

Goda M, Ohata M, Ikoma H, Fujiyoshi Y, Sugimoto M, Fujii R. 2011. Integumental reddish-violet coloration owing to novel dichromatic chromatophores in the teleost fish, Pseudochromis diadema. Pigment Cell \& Melanoma Research 24:614-7. doi: Doi 10.1111/J.1755-148x.2011.00861.X, PMID: WOS:000294019200009

Godin JGJ, McDonough HE. 2003. Predator preference for brightly colored males in the guppy: a viability cost for a sexually selected trait. Behavioral Ecology 14:194-200. doi: 10.1093/beheco/14.2.194, PMID: WOS:000181661100006

Goodrich HB, Greene JM. 1959. An experimental analysis of the development of a color pattern in the fish Brachydanio albolineatus Blyth. J Exp Zool 141:15-45. doi: 10.1002/jez.1401410103, PMID: 13851086

Goodrich HB, Hill GA, Arrick MS. 1941. The Chemical Identification of Gene-Controlled Pigments in Platypoecilus and Xiphophorus and Comparisons with Other Tropical Fish. Genetics 26:573-86. PMID: 17247023

Granneman JG, Kimler VA, Zhang H, Ye X, Luo X, Postlethwait JH, Thummel R. 2017. Lipid droplet biology and evolution illuminated by the characterization of a novel perilipin in teleost fish. eLife 6 . doi: 10.7554/eLife.21771, PMID: 28244868

Green D, Marks AR, Fleischer S, Mclntyre JO. 1996. Wild type and mutant human heart (R)-3hydroxybutyrate dehydrogenase expressed in insect cells. Biochemistry 35:8158-65. doi: 10.1021/bi952807n, PMID: 8679568

Grether GF. 2000. Carotenoid limitation and mate preference evolution: A test of the indicator hypothesis in guppies (Poecilia reticulata). Evolution 54:1712-24. PMID: WOS:000165471000023

Grether GF, Hudon J, Endler JA. 2001. Carotenoid scarcity, synthetic pteridine pigments and the evolution of sexual coloration in guppies (Poecilia reticulata). Proc $R$ Soc B-Biol Sci 268:1245-53. doi: 10.1098/rspb.2001.1624, PMID: WOS:000169471800005

Gur D, Bain EJ, Johnson KR, Aman AJ, Pasoili HA, Flynn JD, Allen MC, Deheyn DD, Lee JC, Lippincott-Schwartz J, Parichy DM. 2020. In situ differentiation of iridophore crystallotypes underlies zebrafish stripe patterning. Nat Commun 11:6391. doi: 10.1038/s41467-020-20088-1, PMID: 33319779

Harrison EH, Kopec RE. 2020. Enzymology of vertebrate carotenoid oxygenases. Biochim Biophys Acta Mol Cell Biol Lipids 1865:158653. doi: 10.1016/j.bbalip.2020.158653, PMID: 32035229 
Hill GE. 1991. Plumage coloration is a sexually selected indicator of male quality. Nature 350:337-9. doi: 10.1038/350337a0, PMID: WOS:A1991FD83800091

Hirata M, Nakamura K, Kanemaru T, Shibata Y, Kondo S. 2003. Pigment cell organization in the hypodermis of zebrafish. Dev Dyn 227:497-503. PMID: 12889058

Houde AE. 1997. Sex, Color, and Mate Choice in Guppies. Princeton, NJ: Princeton University Press.

Hubbard JK, Uy JA, Hauber ME, Hoekstra HE, Safran RJ. 2010. Vertebrate pigmentation: from underlying genes to adaptive function. Trends Genet 26:231-9. doi: 10.1016/j.tig.2010.02.002, PMID: 20381892

Ichikawa Y, Ohtani H, Miura I. 1998. The erythrophore in the larval and adult dorsal skin of the brown frog, Rana ornativentris: Its differentiation, migration, and pigmentary organelle formation. Pigment Cell Research 11:345-54. doi: 10.1111/j.1600-0749.1998.tb00493.x, PMID: WOS:000077515800003

Ide H, Hama T. 1976. Transformation of amphibian iridophores into melanophores in clonal culture. Developmental Biology 53:297-302. doi: 10.1016/0012-1606(76)90232-3, PMID: WOS:A1976CJ97200013

Johnson S, Candolin U. 2017. Predation cost of a sexual signal in the threespine stickleback. Behavioral Ecology 28:1160-5. doi: 10.1093/beheco/arx080,

Kelsh RN, Harris ML, Colanesi S, Erickson CA. 2009. Stripes and belly-spots -- a review of pigment cell morphogenesis in vertebrates. Semin Cell Dev Biol 20:90-104. doi: 10.1016/j.semcdb.2008.10.001, PMID: 18977309

Khalil S, Welklin JF, McGraw KJ, Boersma J, Schwabl H, Webster MS, Karubian J. 2020. Testosterone regulates CYP2J19-linked carotenoid signal expression in male red-backed fairywrens (Malurus melanocephalus). Proc Biol Sci 287:20201687. doi: 10.1098/rspb.2020.1687, PMID: 32933448

Khoo G, Lim TM, Phang VPE. 2012. Ultrastructure of Erythrophores and Xanthophores of the Siamese Fighting Fish, Betta splendens. Isr J Aquacult-Bamid 64. PMID: WOS:000316857900001

Kirischian N, McArthur AG, Jesuthasan C, Krattenmacher B, Wilson JY. 2011. Phylogenetic and functional analysis of the vertebrate cytochrome p450 2 family. $J$ Mol Evol 72:56-71. doi: 10.1007/s00239-010-9402-7, PMID: 21116621

Kullander SO. 2012. Description of Danio flagrans, and redescription of D. choprae, two closely related species from the Ayeyarwaddy River drainage in northern Myanmar (Teleostei: Cyprinidae). Ichthyol Explor Freshw 23:245-62. PMID: WOS:000312624800005

Kullander SO, Fang F. 2009. Danio tinwini, a new species of spotted danio from northern Myanmar (Teleostei: Cyprinidae). Ichthyol Explor Freshw 20:223-8. PMID: WOS:000272708500004

Kullander SO, Noren M. 2016. Danio htamanthinus (Teleostei: Cyprinidae), a new species of miniature cyprinid fish from the Chindwin River in Myanmar. Zootaxa 4178:535-46. doi: 10.11646/zootaxa.4178.4.5, PMID: 27811706

Kullander SO, Rahman MM, Noren M, Mollah AR. 2015. Danio annulosus, a new species of chain Danio from the Shuvolong Falls in Bangladesh (Teleostei: Cyprinidae: Danioninae). Zootaxa 3994:53-68. doi: 10.11646/zootaxa.3994.1.2, PMID: 26250259

Kwan KM, Fujimoto E, Grabher C, Mangum BD, Hardy ME, Campbell DS, Parant JM, Yost HJ, Kanki JP, Chien CB. 2007. The Tol2kit: a multisite gateway-based construction kit for Tol2 transposon transgenesis constructs. Dev Dyn 236:3088-99. doi: 10.1002/dvdy.21343, PMID: 17937395 
Langston HP, Jones L, Churchill S, Churchill PF. 1996. Purification and characterization of a (R)-3hydroxybutyrate dehydrogenase deletion mutant. Evidence for C-terminal involvement in enzyme activation by lecithin. Arch Biochem Biophys 327:45-52. doi: 10.1006/abbi.1996.0091, PMID: 8615695

Lewis VM, Saunders LM, Larson TA, Bain EJ, Sturiale SL, Gur D, Chowdhury S, Flynn JD, Allen MC, Deheyn DD, Lee JC, Simon JA, Lippincott-Schwartz J, Raible DW, Parichy DM. 2019. Fate plasticity and reprogramming in genetically distinct populations of Danio leucophores. Proc Natl Acad Sci U S A 116:11806-11. doi: 10.1073/pnas.1901021116, PMID: 31138706

Li B, Vachali PP, Shen Z, Gorusupudi A, Nelson K, Besch BM, Bartschi A, Longo S, Mattinson T, Shihab S, Polyakov NE, Suntsova LP, Dushkin AV, Bernstein PS. 2017. Retinal accumulation of zeaxanthin, lutein, and beta-carotene in mice deficient in carotenoid cleavage enzymes. Exp Eye Res 159:123-31. doi: 10.1016/j.exer.2017.02.016, PMID: 28286282

Lister JA. 2019. Larval but not adult xanthophore pigmentation in zebrafish requires GTP cyclohydrolase 2 (gch2) function. Pigment Cell \& Melanoma Research 0. doi: 10.1111/pcmr.12783,

Lister JA, Robertson CP, Lepage T, Johnson SL, Raible DW. 1999. nacre encodes a zebrafish microphthalmia-related protein that regulates neural-crest-derived pigment cell fate. Development 126:3757-67. PMID: 10433906

Lopes RJ, Johnson JD, Toomey MB, Ferreira MS, Araujo PM, Melo-Ferreira J, Andersson L, Hill GE, Corbo JC, Carneiro M. 2016. Genetic Basis for Red Coloration in Birds. Curr Biol 26:1427-34. doi: 10.1016/j.cub.2016.03.076, PMID: 27212400

Love MI, Huber W, Anders S. 2014. Moderated estimation of fold change and dispersion for RNAseq data with DESeq2. Genome Biol 15:550. doi: 10.1186/s13059-014-0550-8, PMID: 25516281

Matsumoto J. 1965. Studies on fine structure and cytochemical properties of erythrophores in swordtail, Xiphophorus helleri, with special reference to their pigment granules (Pterinosomes). $J$ Cell Biol 27:493-504. PMID: 5885426 doi: 10.1083/jcb.27.3.493

Matsumoto J, Obika M. 1968. Morphological and biochemical characterization of goldfish erythrophores and their pterinosomes. J Cell Biol 39:233-50. PMID: 5692582

McClure MM, McIntyre PB, McCune AR. 2006. Notes on the natural diet and habitat of eight danionin fishes, including the zebrafish Danio rerio. Journal of Fish Biology 69:553-70. doi: 10.1111/j.1095-8649.2006.01125.x, PMID: WOS:000239961700015

McCluskey BM, Postlethwait JH. 2015. Phylogeny of Zebrafish, a "Model Species," within Danio, a "Model Genus". Mol Biol Evol 32:635-52. doi: 10.1093/molbev/msu325, PMID: 25415969

McCluskey BM, Uji S, Mancusi JL, Postlethwait JH, Parichy DM. 2021. A complex genetic architecture in zebrafish relatives Danio quagga and $\mathrm{D}$. kyathit underlies development of stripes and spots. PLoS Genet 17:e1009364. doi: 10.1371/journal.pgen.1009364, PMID: 33901178

McGraw KJ. Mechanics of Carotenoid-Based Coloration. Bird Coloration Volume I Mechanisms and Measurements. Cambridge MA: Harvard University Press; 2006.

McGraw KJ, Safran RJ, Wakamatsu K. 2005. How feather colour reflects its melanin content. Functional Ecology 19:816-21. doi: https://doi.org/10.1111/j.1365-2435.2005.01032.x,

McMenamin SK, Bain EJ, McCann AE, Patterson LB, Eom DS, Waller ZP, Hamill JC, KuhIman JA, Eisen JS, Parichy DM. 2014. Thyroid hormone-dependent adult pigment cell lineage and pattern in zebrafish. Science 345:1358-61. doi: 10.1126/science.1256251, PMID: 25170046

Milinski M, Bakker TCM. 1990. Female sticklebacks use male coloration in mate choice and hence avoid parasitized males. Nature 344:330-3. doi: 10.1038/344330a0, PMID:

WOS:A1990CV28900063 
Mundy NI, Stapley J, Bennison C, Tucker R, Twyman H, Kim KW, Burke T, Birkhead TR, Andersson S, Slate J. 2016. Red Carotenoid Coloration in the Zebra Finch Is Controlled by a Cytochrome P450 Gene Cluster. Curr Biol 26:1435-40. doi: 10.1016/j.cub.2016.04.047, PMID: 27212402

Niu MC. 1954. Further studies on the origin of amphibian pigment cells. Journal of Experimental Zoology 125:199-220. doi: 10.1002/jez.1401250203,

Odenthal J, Rossnagel K, Haffter P, Kelsh RN, Vogelsang E, Brand M, van Eeden FJM, FurutaniSeiki M, Granato M, Hammerschmidt C-P, Jiang Y-J, Kane DA, Kelsh RN, Mullins MC, NussleinVolhard C. Mutations affecting xanthophore pigmentation in the zebrafish, Danio rerio. Development1996. p. 391-8.

Olsson M, Stuart-Fox D, Ballen C. 2013. Genetics and evolution of colour patterns in reptiles. Semin Cell Dev Biol 24:529-41. doi: 10.1016/j.semcdb.2013.04.001, PMID: 23578866

Olsson M, Stuart-Fox D, Ballen C. 2013. Genetics and evolution of colour patterns in reptiles. Seminars in Cell \& Developmental Biology 24:529-41. doi: 10.1016/j.semcdb.2013.04.001

Oshima N, Kasai A. 2002. Iridophores involved in generation of skin color in the zebrafish, Brachydanio rerio. Forma 17:91-101.

Otsuka H, Kimura T, Ago Y, Nakama M, Aoyama Y, Abdelkreem E, Matsumoto H, Ohnishi H, Sasai H, Osawa M, Yamaguchi S, Mitchell GA, Fukao T. 2020. Deficiency of 3-hydroxybutyrate dehydrogenase $(\mathrm{BDH} 1)$ in mice causes low ketone body levels and fatty liver during fasting. $J$ Inherit Metab Dis 43:960-8. doi: 10.1002/jimd.12243, PMID: 32279332

Parichy DM. 2021. Evolution of pigment cells and patterns: recent insights from teleost fishes. Curr Opin Genet Dev 69:88-96. doi: 10.1016/j.gde.2021.02.006, PMID: 33743392

Parichy DM, Ransom DG, Paw B, Zon LI, Johnson SL. 2000. An orthologue of the kit-related gene $\mathrm{fms}$ is required for development of neural crest-derived xanthophores and a subpopulation of adult melanocytes in the zebrafish, Danio rerio. Development 127:3031-44. PMID: 10862741

Parichy DM, Turner JM. 2003. Temporal and cellular requirements for Fms signaling during zebrafish adult pigment pattern development. Development 130:817-33. PMID: 12538511

Patterson LB, Parichy DM. 2019. Zebrafish Pigment Pattern Formation: Insights into the Development and Evolution of Adult Form. Annu Rev Genet 53:505-30. doi: 10.1146/annurevgenet-112618-043741, PMID: 31509458

Persson B, Kallberg Y, Bray JE, Bruford E, Dellaporta SL, Favia AD, Duarte RG, Jornvall H, Kavanagh KL, Kedishvili N, Kisiela M, Maser E, Mindnich R, Orchard S, Penning TM, Thornton JM, Adamski J, Oppermann U. 2009. The SDR (short-chain dehydrogenase/reductase and related enzymes) nomenclature initiative. Chem Biol Interact 178:94-8. doi: 10.1016/j.cbi.2008.10.040, PMID: 19027726

Poliakov E, Uppal S, Rogozin IB, Gentleman S, Redmond TM. 2020. Evolutionary aspects and enzymology of metazoan carotenoid cleavage oxygenases. Biochim Biophys Acta Mol Cell Biol Lipids 1865:158665. doi: 10.1016/j.bbalip.2020.158665, PMID: 32061750

Pryke SR, Griffith SC. 2006. Red dominates black: agonistic signalling among head morphs in the colour polymorphic Gouldian finch. Proceedings of the Royal Society B: Biological Sciences 273:949-57. doi: 10.1098/rspb.2005.3362,

Quigley IK, Manuel JL, Roberts RA, Nuckels RJ, Herrington ER, MacDonald EL, Parichy DM. 2005. Evolutionary diversification of pigment pattern in Danio fishes: differential fms dependence and stripe loss in D. albolineatus. Development 132:89-104. doi: 10.1242/dev.01547, PMID: 15563521

Salis P, Lorin T, Lewis V, Rey C, Marcionetti A, Escande ML, Roux N, Besseau L, Salamin N, Semon M, Parichy D, Volff JN, Laudet V. 2019. Developmental and comparative transcriptomic 
identification of iridophore contribution to white barring in clownfish. Pigment Cell Melanoma Res 32:391-402. doi: 10.1111/pcmr.12766, PMID: 30633441

Saunders LM, Aman AJ, Mishra AK, Lewis VM, Toomey MB, Packer JS, Qiu X, McFaline-Figueroa JL, Corbo JC, Trapnell C, Parichy DM. 2019. Thyroid hormone regulates distinct paths to maturation in pigment cell lineages. eLife 8:e45181.

Schartl M, Larue L, Goda M, Bosenberg MW, Hashimoto H, Kelsh RN. 2016. What is a vertebrate pigment cell? Pigment Cell Melanoma Res 29:8-14. doi: 10.1111/pcmr.12409, PMID: 26247887

Schindelin J, Arganda-Carreras I, Frise E, Kaynig V, Longair M, Pietzsch T, Preibisch S, Rueden C, Saalfeld S, Schmid B, Tinevez JY, White DJ, Hartenstein V, Eliceiri K, Tomancak P, Cardona A. 2012. Fiji: an open-source platform for biological-image analysis. Nat Methods 9:676-82. doi: 10.1038/nmeth.2019, PMID: 22743772

Sefc KM, Brown AC, Clotfelter ED. 2014. Carotenoid-based coloration in cichlid fishes. Comp Biochem Physiol A Mol Integr Physiol 173C:42-51. doi: 10.1016/j.cbpa.2014.03.006, PMID: 24667558

Shah AN, Davey CF, Whitebirch AC, Miller AC, Moens CB. 2015. Rapid reverse genetic screening using CRISPR in zebrafish. Nat Methods. doi: 10.1038/nmeth.3360, PMID: 25867848

Singh AP, Dinwiddie A, Mahalwar P, Schach U, Linker C, Irion U, Nusslein-Volhard C. 2016. Pigment Cell Progenitors in Zebrafish Remain Multipotent through Metamorphosis. Dev Cell 38:316-30. doi: 10.1016/j.devcel.2016.06.020, PMID: 27453500

Singh AP, Schach U, Nusslein-Volhard C. 2014. Proliferation, dispersal and patterned aggregation of iridophores in the skin prefigure striped colouration of zebrafish. Nat Cell Biol 16:607-14. doi: 10.1038/ncb2955, PMID: 24776884

Spiewak JE, Bain EJ, Liu J, Kou K, Sturiale SL, Patterson LB, Diba P, Eisen JS, Braasch I, Ganz J, Parichy DM. 2018. Evolution of Endothelin signaling and diversification of adult pigment pattern in Danio fishes. PLoS Genet 14:e1007538. doi: 10.1371/journal.pgen.1007538, PMID: 30226839

Stevens M, Ruxton GD. 2012. Linking the evolution and form of warning coloration in nature. Proc Biol Sci 279:417-26. doi: 10.1098/rspb.2011.1932, PMID: 22113031

Strange C, editor. Carotenoids in Nature: Biosynthesis, Regulation and Function. Switzerland: Springer; 2016.

Suster ML, Kikuta H, Urasaki A, Asakawa K, Kawakami K. 2009. Transgenesis in zebrafish with the tol2 transposon system. Methods Mol Biol 561:41-63. doi: 10.1007/978-1-60327-019-9_3, PMID: 19504063

Svensson PA, Wong BBM. 2011. Carotenoid-based signals in behavioural ecology: a review. Behaviour 148:131-89. doi: 10.1163/000579510x548673, PMID: WOS:000288105500001

Takahashi D. 2018. Female Mate Choice Based on Male Nuptial Coloration in Pale Chub, Zacco platypus. Zoological Science 35:23-7. doi: 10.2108/zs170102, PMID: WOS:000424773100002

Tang KL, Agnew MK, Hirt MV, Sado T, Schneider LM, Freyhof J, Sulaiman Z, Swartz E, Vidthayanon C, Miya M, Saitoh K, Simons AM, Wood RM, Mayden RL. 2010. Systematics of the subfamily Danioninae (Teleostei: Cypriniformes: Cyprinidae). Mol Phylogenet Evol 57:189-214. doi: 10.1016/j.ympev.2010.05.021, PMID: 20553898

Toews DP, Hofmeister NR, Taylor SA. 2017. The Evolution and Genetics of Carotenoid Processing in Animals. Trends Genet 33:171-82. doi: 10.1016/j.tig.2017.01.002, PMID: 28174022

Toomey MB, Lopes RJ, Araujo PM, Johnson JD, Gazda MA, Afonso S, Mota PG, Koch RE, Hill GE, Corbo JC, Carneiro M. 2017. High-density lipoprotein receptor SCARB1 is required for carotenoid 
coloration in birds. Proc Natl Acad Sci U S A 114:5219-24. doi: 10.1073/pnas.1700751114, PMID: 28465440

Toomey MB, Marques CI, Andrade P, Araujo PM, Sabatino S, Gazda MA, Afonso S, Lopes RJ, Corbo JC, Carneiro M. 2018. A non-coding region near Follistatin controls head colour polymorphism in the Gouldian finch. Proc Biol Sci 285. doi: 10.1098/rspb.2018.1788, PMID: 30282656

Tryon RC, Higdon CW, Johnson SL. 2011. Lineage relationship of direct-developing melanocytes and melanocyte stem cells in the zebrafish. PLOS ONE 6:e21010. doi: 10.1371/journal.pone.0021010, PMID: 21698209

Tu S, Johnson SL. 2010. Clonal analyses reveal roles of organ founding stem cells, melanocyte stem cells and melanoblasts in establishment, growth and regeneration of the adult zebrafish fin. Development 137:3931-9. doi: 10.1242/dev.057075, PMID: 20980402

Tu S, Johnson SL. 2011. Fate restriction in the growing and regenerating zebrafish fin. Dev Cell 20:725-32. doi: 10.1016/j.devcel.2011.04.013, PMID: 21571228

Twyman H, Andersson S, Mundy NI. 2018. Evolution of CYP2J19, a gene involved in colour vision and red coloration in birds: positive selection in the face of conservation and pleiotropy. BMC Evol Biol 18:22. doi: 10.1186/s12862-018-1136-y, PMID: 29439676

Twyman H, Valenzuela N, Literman R, Andersson S, Mundy NI. 2016. Seeing red to being red: conserved genetic mechanism for red cone oil droplets and co-option for red coloration in birds and turtles. Proc Biol Sci 283. doi: 10.1098/rspb.2016.1208, PMID: 27488652

von Lintig J, Hessel S, Isken A, Kiefer C, Lampert JM, Voolstra O, Vogt K. 2005. Towards a better understanding of carotenoid metabolism in animals. Biochim Biophys Acta 1740:122-31. doi: 10.1016/j.bbadis.2004.11.010, PMID: 15949678

Weaver RJ, Koch RE, Hill GE. 2017. What maintains signal honesty in animal colour displays used in mate choice? Philos Trans R Soc Lond B Biol Sci 372. doi: 10.1098/rstb.2016.0343, PMID: 28533460

Weaver RJ, Santos ESA, Tucker AM, Wilson AE, Hill GE. 2018. Carotenoid metabolism strengthens the link between feather coloration and individual quality. Nat Commun 9:73. doi: 10.1038/s41467017-02649-Z, PMID: 29311592

Wedekind C, Meyer P, Frischknecht M, Niggli UA, Pfander H. 1998. Different carotenoids and potential information content of red coloration of male three-spined stickleback. Journal of Chemical Ecology 24:787-801. doi: 10.1023/a:1022365315836, PMID: WOS:000073520700002

Weiss SL, Foerster K, Hudon J. 2012. Pteridine, not carotenoid, pigments underlie the femalespecific orange ornament of striped plateau lizards (Sceloporus virgatus). Comparative Biochemistry and Physiology B-Biochemistry \& Molecular Biology 161:117-23. doi: 10.1016/j.cbpb.2011.10.004, PMID: WOS:000300069500004

Widjaja-Adhi MA, Lobo GP, Golczak M, Von Lintig J. 2015. A genetic dissection of intestinal fatsoluble vitamin and carotenoid absorption. Hum Mol Genet 24:3206-19. doi: 10.1093/hmg/ddv072, PMID: 25701869

Yates AD, Achuthan P, Akanni W, Allen J, Allen J, Alvarez-Jarreta J, Amode MR, Armean IM, Azov AG, Bennett R, Bhai J, Billis K, Boddu S, Marugan JC, Cummins C, Davidson C, Dodiya K, Fatima R, Gall A, Giron CG, Gil L, Grego T, Haggerty L, Haskell E, Hourlier T, Izuogu OG, Janacek SH, Juettemann T, Kay M, Lavidas I, Le T, Lemos D, Martinez JG, Maurel T, McDowall M, McMahon A, Mohanan S, Moore B, Nuhn M, Oheh DN, Parker A, Parton A, Patricio M, Sakthivel MP, Abdul Salam AI, Schmitt BM, Schuilenburg H, Sheppard D, Sycheva M, Szuba M, Taylor K, Thormann A, Threadgold G, Vullo A, Walts B, Winterbottom A, Zadissa A, Chakiachvili M, Flint B, Frankish A, 
bioRxiv preprint doi: https://doi.org/10.1101/2021.05.11.443569; this version posted May 11, 2021. The copyright holder for this preprint (which

was not certified by peer review) is the author/funder, who has granted bioRxiv a license to display the preprint in perpetuity. It is made available under aCC-BY-NC-ND 4.0 International license.

Hunt SE, G II, Kostadima M, Langridge N, Loveland JE, Martin FJ, Morales J, Mudge JM, Muffato M, Perry E, Ruffier M, Trevanion SJ, Cunningham F, Howe KL, Zerbino DR, Flicek P. 2020. Ensembl 2020. Nucleic Acids Res 48:D682-D8. doi: 10.1093/nar/gkz966, PMID: 31691826

Ziegler I. 2003. The pteridine pathway in zebrafish: regulation and specification during the determination of neural crest cell-fate. Pigment Cell Res 16:172-82. PMID: 12753383 
Figure 1. Carotenoid types and distribution of red erythrophores among Danio species. (A)

Examples of major carotenoid types including yellow zeaxanthin, red astaxanthin, and orange $\beta$-carotene, with factors required for entry into cells and chemical modification (Main text). (B) Erythrophore presence (red circles) or absence (light grey circles) indicated by direct observation or prior species descriptions (Spiewak et al.; Fang and Kottelat, 2000; Quigley et al., 2005; Engeszer et al., 2007; Kullander and Fang, 2009; Kullander, 2012; Kullander and Noren, 2016; McCluskey et al., 2021). A composite phylogeny based on several molecular evolutionary studies is shown; grey branches indicate lineage placements inferred by morphology alone (Tang et al., 2010; Kullander, 2012; Kullander et al., 2015; McCluskey and Postlethwait, 2015). Grey boxes across branches indicate lineages in which erythrophores are inferred most parsimoniously to have been lost. (C) Anal fin details of zebrafish (rerio) without erythrophores and other species with erythrophores. Cells are shown in their typical native states, with pigment dispersed, and following treatment with epinephrine, which causes pigment to be contracted towards cell centers. Scale bar: $100 \mu \mathrm{m}$.

A
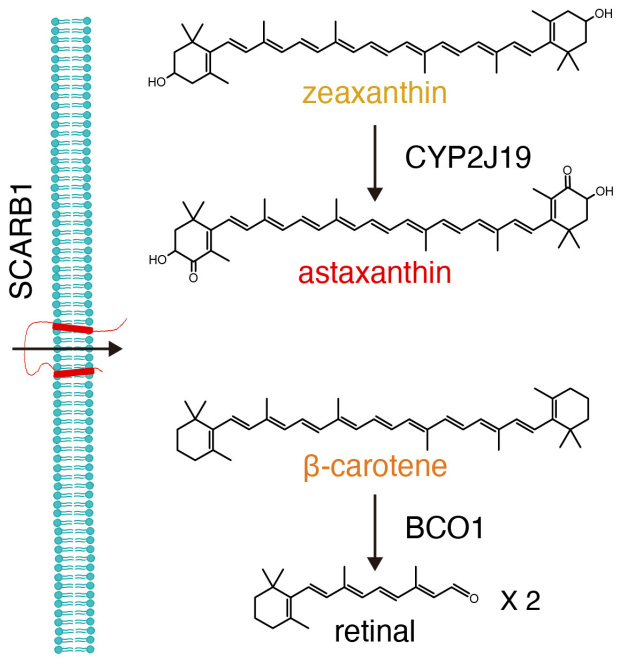

C
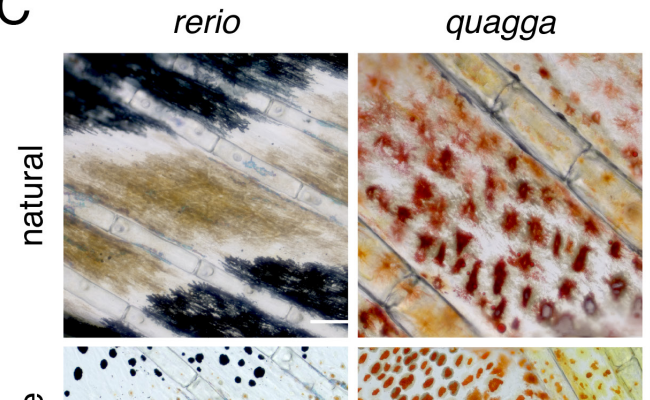

这
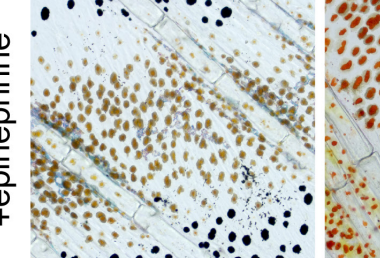

B

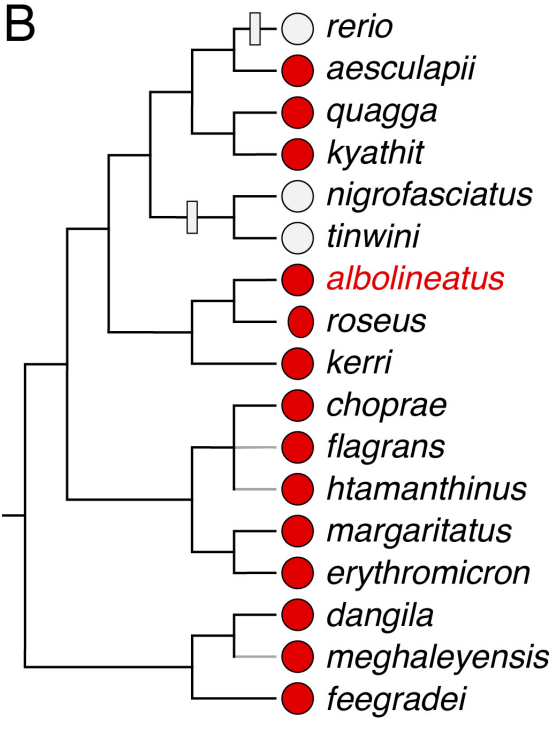

margaritatus

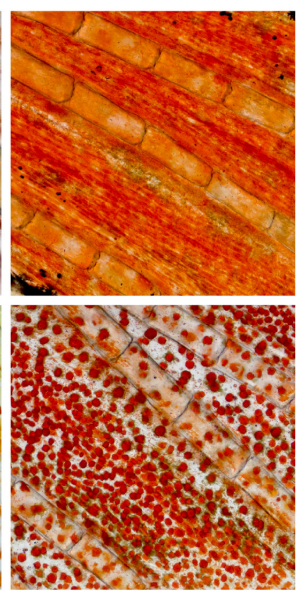

erythromicron

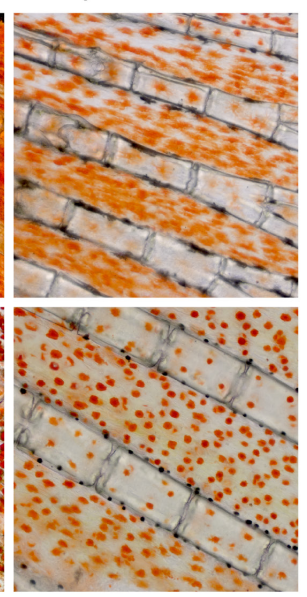


Figure 2. Anal fin pigment pattern of $D$. albolineatus and its ontogeny. (A) Erythrophores were present on the body and were particularly evident on the anal fin (closeup at right), where these cells were found more proximally than yellow xanthophores. (B) At larval stages xanthophore-like cells with a uniform orange coloration occurred across the entire fin (left panels). Later in the adult, proximal red erythrophores and distal yellow xanthophores have distinct colors (middle and right panels). (C) Erythrophores and xanthophores had different spectra under epiflourescence.

Erythrophores autofluorescenced in red (displayed in magenta) whereas xanthophores autofluoresced in green. (D) Hue values of HSB color space under brightfield illumination were correlated with ratios of red to green autofluorescence $\left(R^{2}=0.92, P<0.0001\right)$. (E) Colors of cells varied across the proximodistal axis of the fin, shown as relative position with fin base at 0 and fin tip at 1 . Erythrophores in proximal regions were distinct in both color spaces from xanthophores in distal regions though some integration was evident in middle regions, near the melanophore stripe. $N=250$ cells from 5 adult males in D and E. Color fills represent red to green fluorescence ratios. (F) During the larva-to-adult transformation, ratios of red to green autofluorescence diverged between prospective erythrophore and xanthophore regions. Individual red and yellow points correspond to mean values of cells in in proximal and distal regions, respectively, from each of 31 male or female fish ( $N=620$ cells total) imaged at a range of developmental stages represented by different standard lengths (SL). Scale bars: $5 \mathrm{~mm}$ (A, left), $1 \mathrm{~mm}$ (A, right); $25 \mu \mathrm{m}$ (B, C).

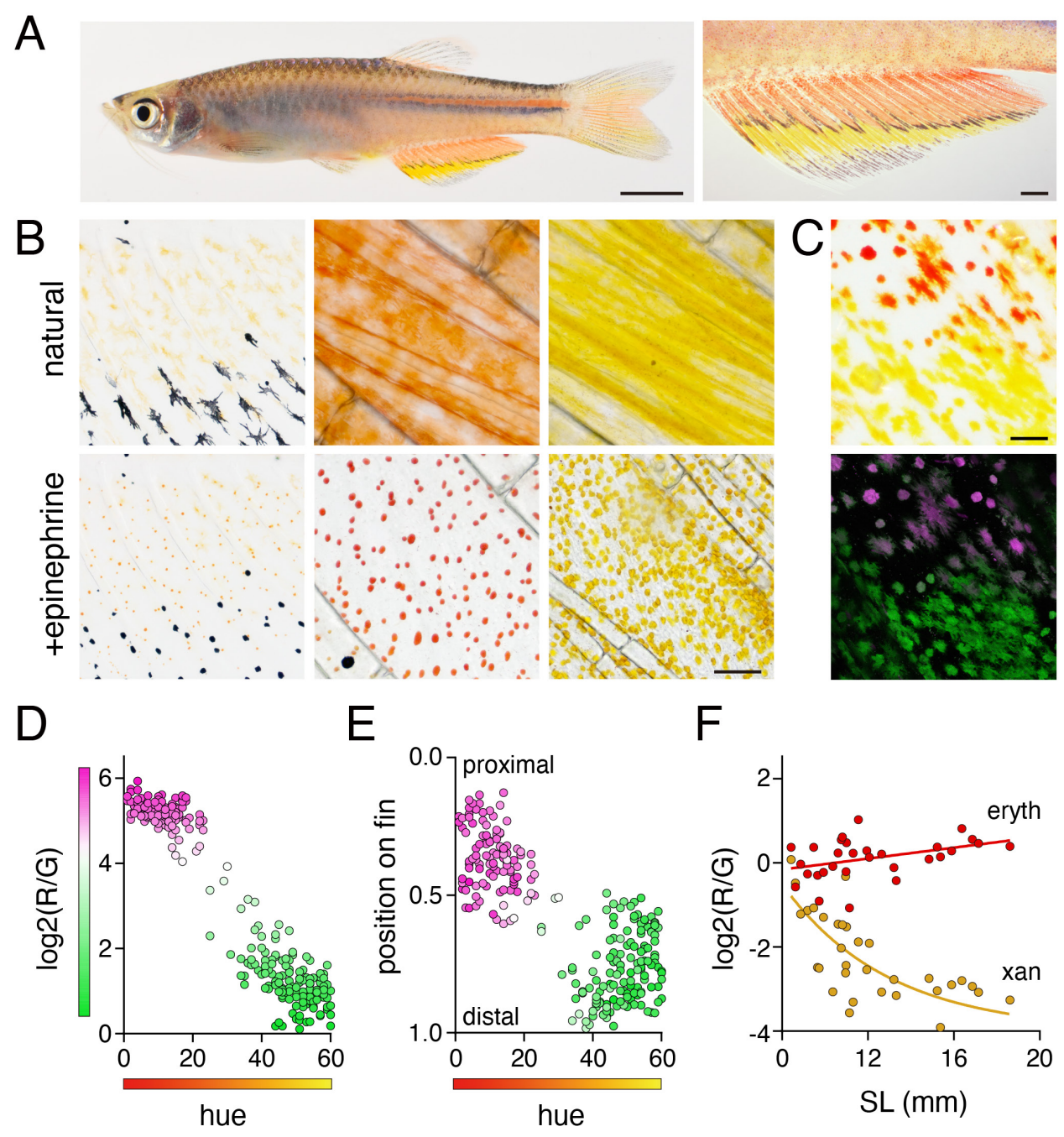


Figure 2 - figure supplement 1. Sex and age differences in erythrophore pigmentation and occurrence of a binucleated state. (A) Erythrophores of female fish were paler than erythrophores of male fish (compare to B and Figure 2A). (B) Melanophores stripes disappeared in older adult males (compared to Figure 2A). (C) Erythrophores (left) though not xanthophores (right) were often binucleated, here revealed by transgenic expression of nuclear-localizing aox5:nucEosFP (see Main text). Red and yellow pigments have been contracted towards cell centers by epinephrine treatment. Multiple nuclei are indicated by arrowheads. (D) Cell densities diverged in proximal and distal regions of the anal fin as fish and fins developed. SL, standard length. Shown are average of cells observed in 3 regions of $10^{-2} \mathrm{~mm}^{2}$ prospective erythrophore (proximal) or xanthophore (distal) regions of 31 fish representing a range of stages ( $N=620$ cells total). Scale bars: $2 \mathrm{~mm}(\mathbf{A}, \mathbf{B}) ; 50 \mu \mathrm{m}$ (C).
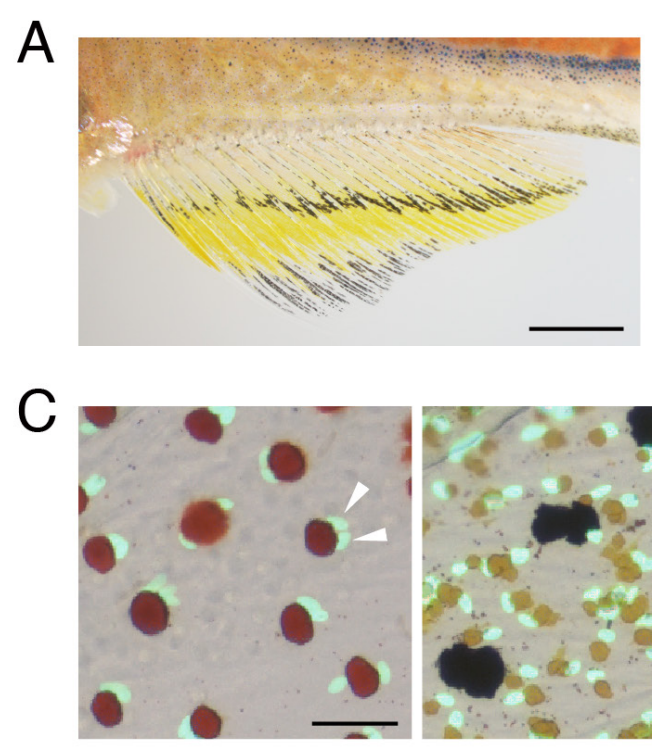
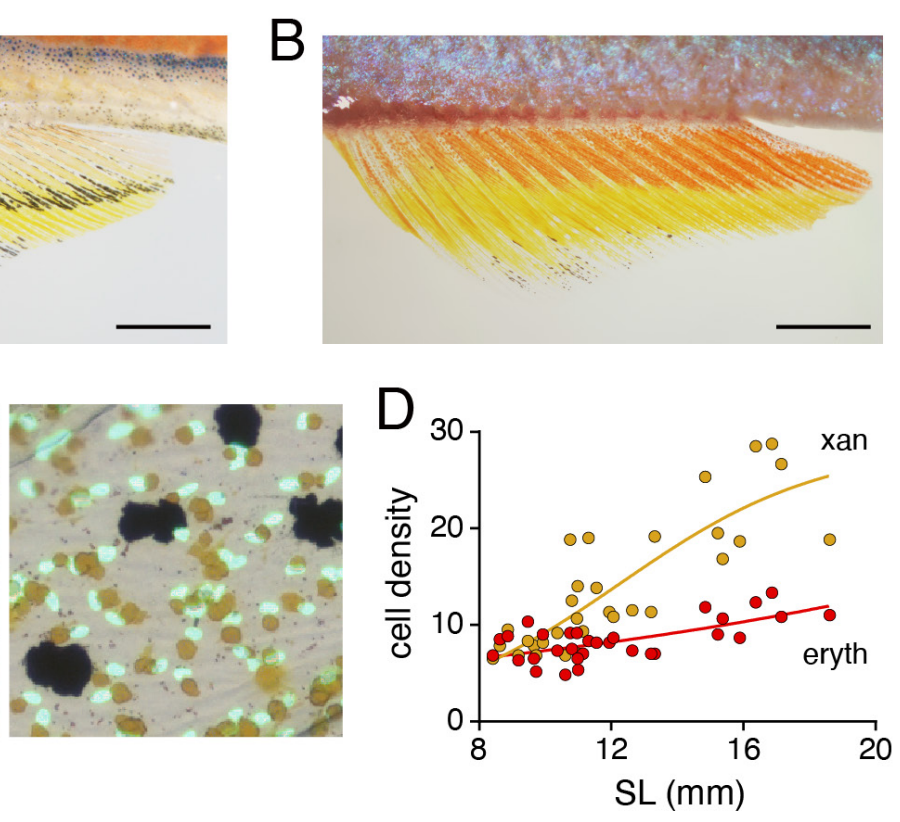
bioRxiv preprint doi: https://doi.org/10.1101/2021.05.11.443569; this version posted May 11, 2021. The copyright holder for this preprint (which

was not certified by peer review) is the author/funder, who has granted bioRxiv a license to display the preprint in perpetuity. It is made available under aCC-BY-NC-ND 4.0 International license.

Figure 2 - figure supplement 2. Pattern development in anal fins of larva to juvenile fish. Melanophores were the first pigment cells evident $(7.0 \mathrm{~mm} \mathrm{SL})$. Subsequently xanthophore-like cells with orange coloration were found across the fin except in distalmost regions that were enriched instead in melanophores ( $8.4 \mathrm{~mm} \mathrm{SL})$. With additional growth and development, proximal and distal cells diverged in cell color and density $(13.3 \mathrm{~mm} \mathrm{SL})$, whereas melanophores consolidated into a stripe pattern centrally, as described previously (Goodrich and Greene, 1959). Colors of prospective erythrophores and xanthophores were indistinguishable prior to $12 \mathrm{~mm} \mathrm{SL}$. Scale bars: $200 \mu \mathrm{m}$ (left), $50 \mu \mathrm{m}$ (right).
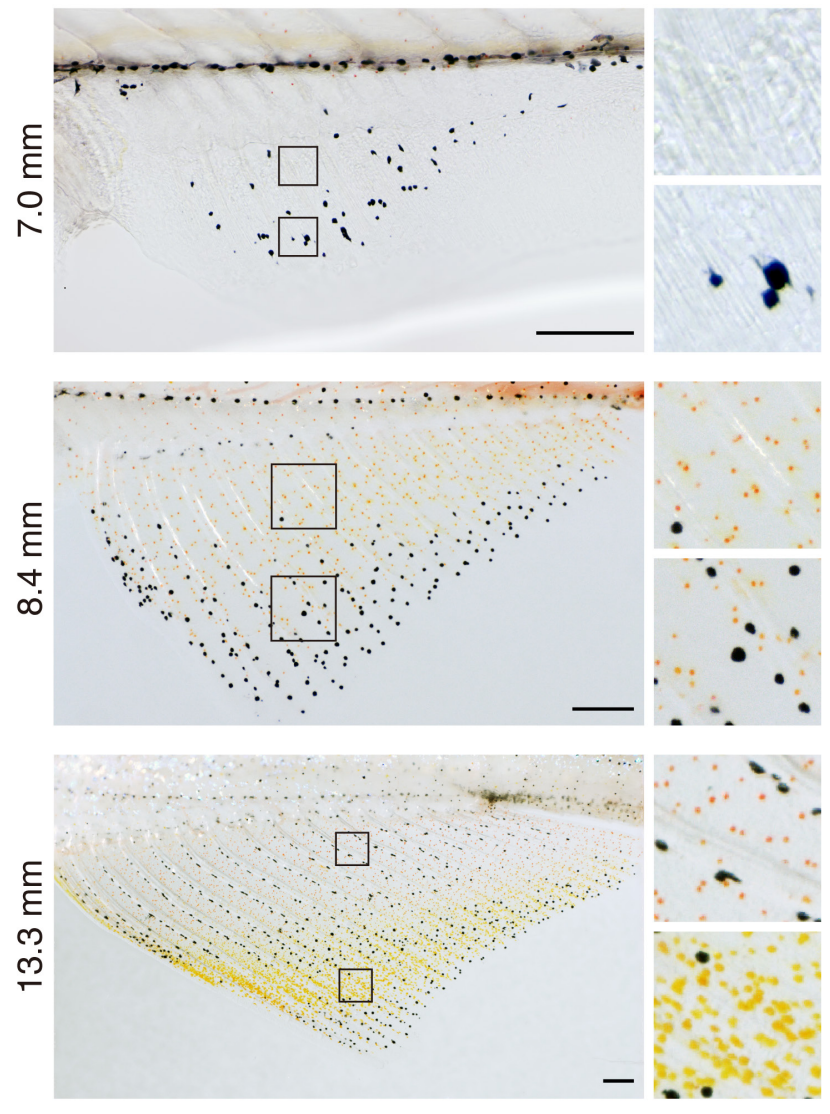
Figure 3. Shared progenitor of fin erythrophores and xanthophores revealed by clonal analyses. (A) In fish mosaic for somatically induced mutations in scarb1 most rare, wild-type clones consisted of both erythrophores and xanthophores (8 of 10 presumptive clones in 7 fish analyzed, with remaining clones only containing one or the other cell type). (B) Clonal labeling of xanthophores and erythophores with aox5:palmEGFP. In the clone shown here, an initial complement of several orange cells at the level of the melanophore stripe $(\mathrm{d} 0,7.5 \mathrm{~mm} \mathrm{SL})$ expanded to include more cells proximally and distally to the melanophore stripe that differentiated as erythrophores and xanthophores, respectively (d36, $15 \mathrm{~mm} \mathrm{SL}$; red arrowheads). Example shown here was representative of 22 out of 24 clones in 18 fish, consistent with observations in zebrafish (Tu and Johnson, 2010; Tu and Johnson, 2011); an additional 10 clones only contained erythrophores, 1 clone only had xanthophores. (C) When aox5:nucEosFP+ cells on the body were bulk photoconverted before fin development, only unconverted aox5:nucEosFP+ cells (green nuclei) were present in the fin $4 \mathrm{~d}$ later (images representative of all $N=3$ fish tested). (D) Successive steps in anal fin development and erythrophore/xanthophore lineage specification revealed many cells newly acquiring aox5:nucEosFP expression at daily intervals within the fin (green nuclei). Though some aox5:nucEosFP+ cells were present at the fin base these did not enter into the fin proper (white cells, arrowheads; images shown are from a single individual representative of all $N=7$ fish tested in this manner over 23 days each). Scale bars: $200 \mu \mathrm{m}$ (A, B); $100 \mu \mathrm{m}$ (C, D).
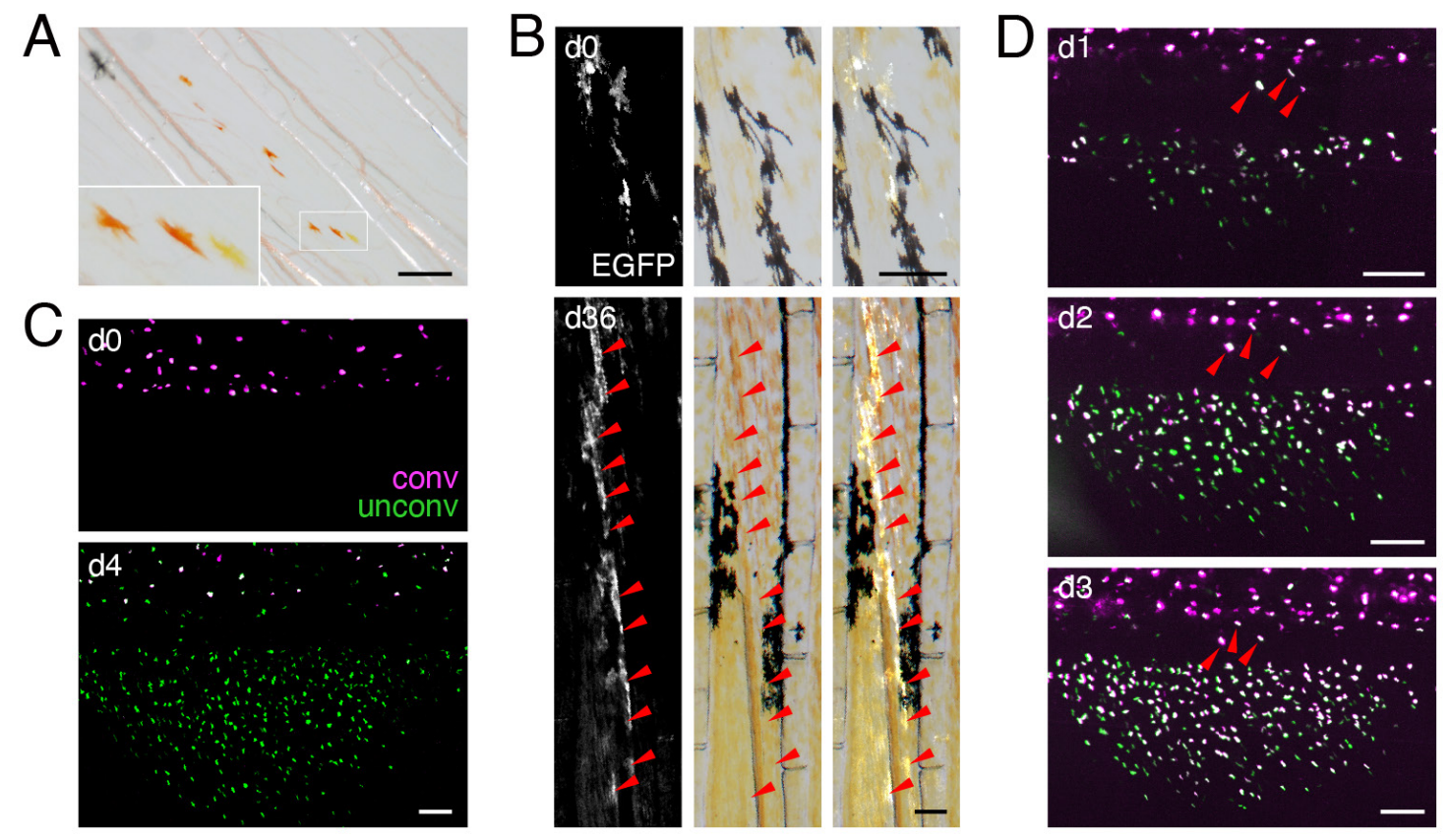
Figure 4. Bipotential precursor to erythrophores and xanthophores revealed in the fin by fate mapping. (A) Unpigmented cells of the xanthophore lineage, marked by aox5:nucEosFP transgene expression (see Main text), present at $7.0 \mathrm{~mm}$ SL had acquired a pale orange color 1 day later. (Representative of all $N=7$ fish examined by repeated imaging during larval development). Insets show higher magnification images of a corresponding region. (B) Example of a photoconverted, initially unpigmented cell ( $\mathrm{d} 0,7.0 \mathrm{~mm} \mathrm{SL})$ that yielded a clone containing both erythrophores and xanthophores (d35, $15.0 \mathrm{~mm}$ SL; representative of 4 of 7 clones, with remaining clones containing erythrophores only). Fish were treated with epinephrine to contract pigment before imaging. Arrows indicate erythrophore autofluorescence from red carotenoid pigment. Inserts, proximal and distal cells in the clone. (C) Percentages of clones containing only erythrophores, only xanthophores, or both cell types. Numbers above bars indicate clone sample sizes examined. In these analyses pigment cells and progenitors stably expressed aox5:nucEosFP $(7.5,8.5 \mathrm{~mm} \mathrm{SL})$ or were injected to mosaically express a different transgene mitfa:nucEosFP $(7.0 \mathrm{~mm} \mathrm{SL})$. In zebrafish, mitfa (melanophore-inducing transcription factor a) is expressed by pigment cell progenitors, as well as melanophores and xanthophores (Lister et al., 1999; Budi et al., 2011; Saunders et al., 2019), and we found in $D$. albolineatus that mitfa:nucEosFP was expressed in these cells as well as orange cells of larvae and erythrophores of adults. mitfa:nucEosFP was used for fate mapping at early stages owing to its more robust expression in unpigmented cells. Scale bar: $50 \mu \mathrm{m}$.
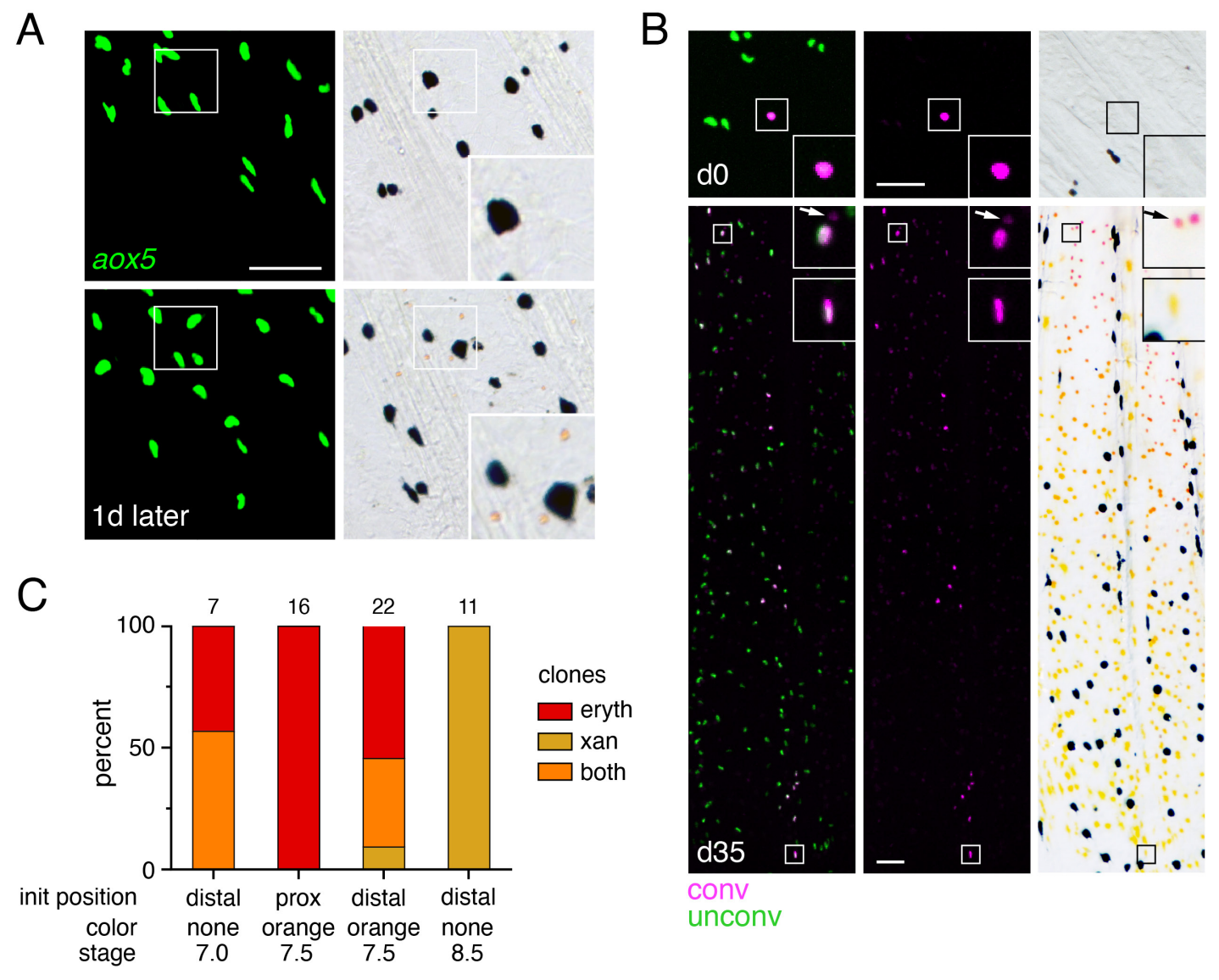

conv unconv 
Figure 4 - figure supplement 1. Fate mapping of single photoconverted cells at different locations and stages. Representative examples of additional classes of clones shown in Figure 4C. (A) An orange cell initially in the proximal fin that generated daughters remaining proximally developing only as erythrophores. (B) An initially distal orange cell that generated a clone including both proximal erythrophores and distal xanthophores. (C) An unpigmented cell at a later stage of fin development initially distal to the melanophore stripe (Figure 1A), produced only generated xanthophores. Scale bar: $50 \mu \mathrm{m}$.

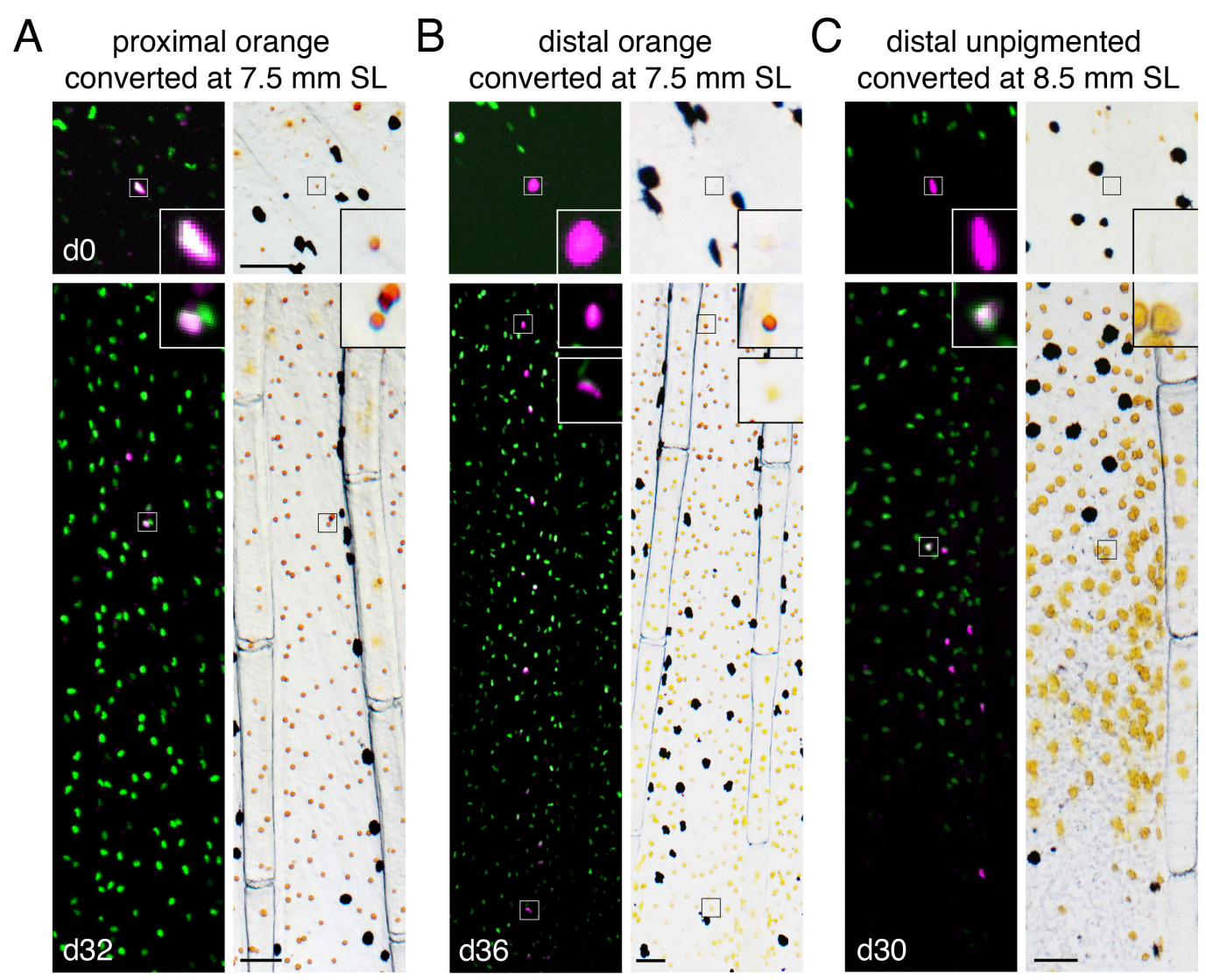


Figure 5. Regeneration assays reveal fate plasticity in differentiated cells and latent stem cells competent to differentiate as erythrophores and xanthophores. (A) Brightfield sequence of regeneration with illustrating apparent conversion of erythophores to xanthophores (image series representative of all $N=3$ fish examined by repeated imaging through regeneration). As fins regenerated, individual erythrophores (circled) near the amputation plane appeared to divide, with presumptive daughter cells having reduced amounts of pigment visible upon contraction with epinephrine and an increasingly yellow-orange color. (B) Schematic of regeneration experiment in C. Fins of $\operatorname{Tg}($ aox $5: n u c E o s F P)$ fish were photo-converted in toto prior to amputation through the erythrophore region. Fins regenerated over 15 days and pigment pattern had re-formed by 30 days, at which time a new melanophore stripe and distinct regions of erythrophores and xanthophores had developed. (C) Example of cells in regenerative tissue 36 days post-amputation (dpa). Regenerative xanthophores near the plane of amputation often contained photoconverted nucEosFP in a region of fin extending $400 \mu \mathrm{m}$ from the distalmost red erythrophore into the regenerative xanthophore region (means $\pm 95 \%$ confidence interval; $N=1964$ cells in 4 fish examined). Dashed lines indicate amputation in B and C. Scale bars: $50 \mu \mathrm{m}(A) ; 100 \mu \mathrm{m}(C)$.
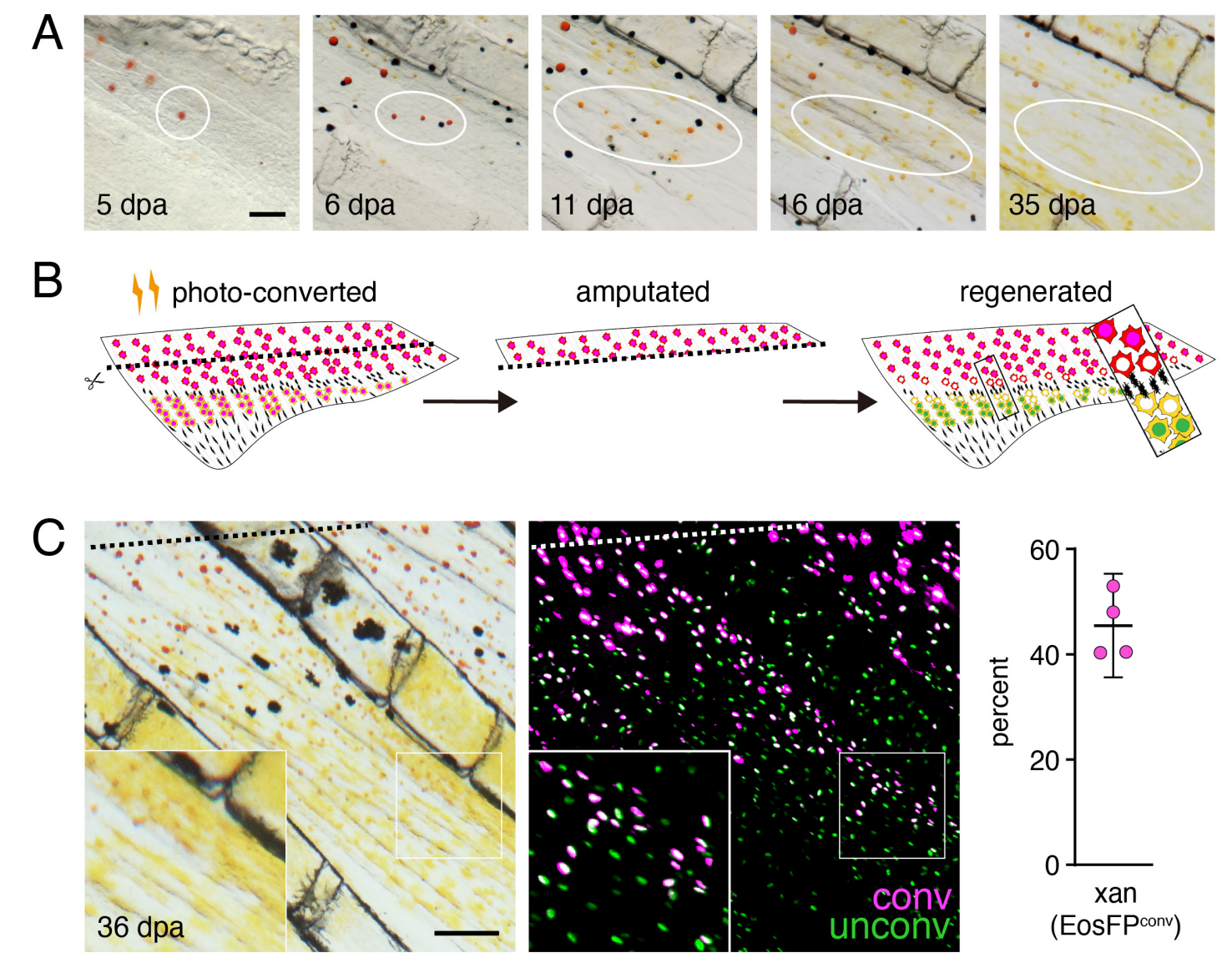
Figure 5 - figure supplement 1. Regeneration of erythrophores from newly specified unpigmented progenitors. (A) Prior to regeneration, only erythrophores expressed aox5:nucEosFP in proximal regions; unpigmented aox5:nucEosFP+ cells were not evident, indicating that cells marked by photoconversion post-amputation were derived from previously differentiated erythrophores. Top, brightfield merged with bottom fluorescent image. (B) Brightfield and fluorescence (single channel at bottom, merged top right) showing erthyrophore nuclei adjacent to contracted pigment granules. Some nuclei retained photoconverted nucEosFP (magenta; white arrows), indicating cells were present prior to amputation, whereas other nuclei were labeled only with photoconverted nucEosFP (green; green arrows), indicating de novo differentiation during regeneration. Newly differentiating erythrophores were rare, however, in this example found only in 2 of 10 interray regions of the fish examined and only in relatively proximal locations. Scale bar: 200 $\mu \mathrm{m}(\mathrm{A}) ; 50 \mu \mathrm{m}(\mathrm{B})$.
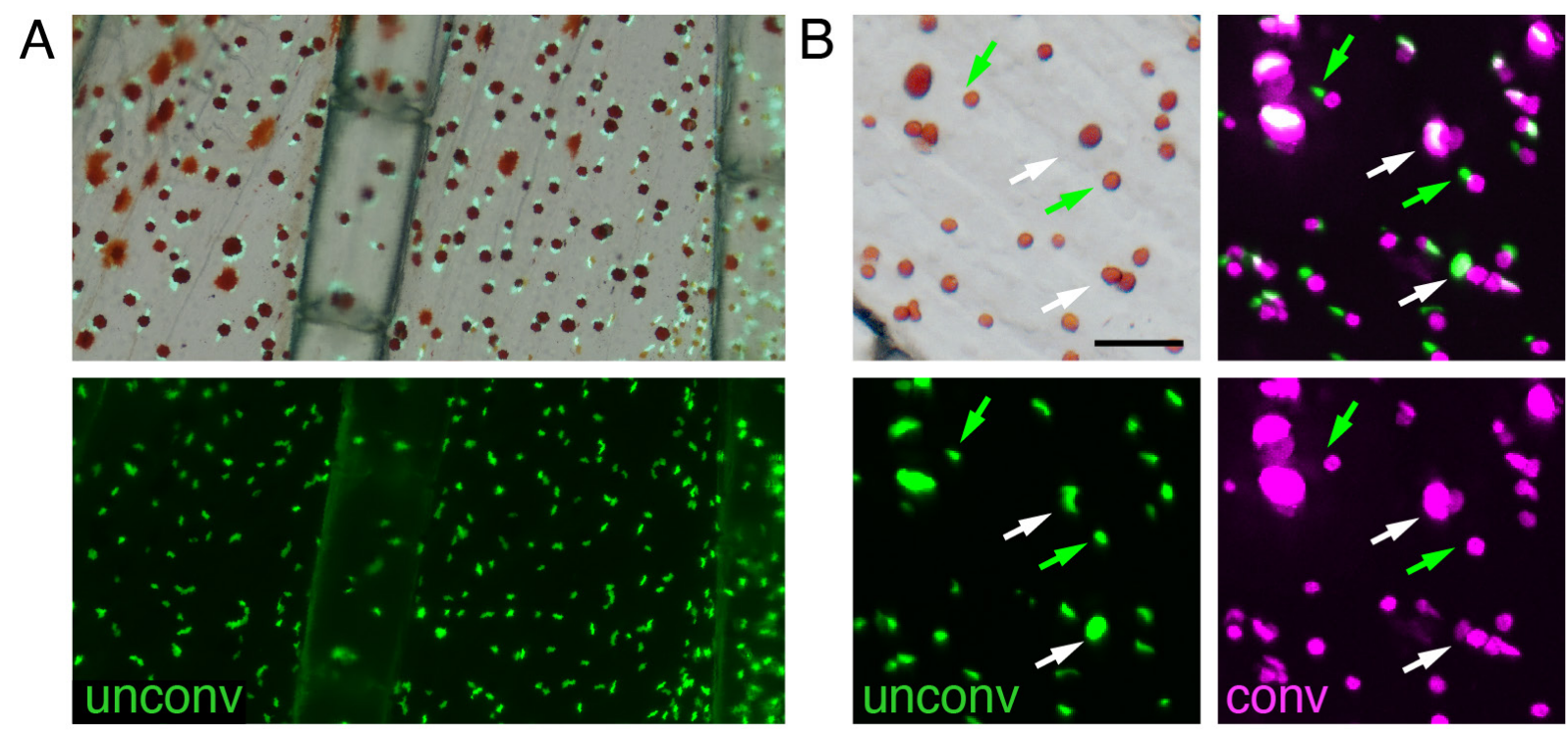
bioRxiv preprint doi: https://doi.org/10.1101/2021.05.11.443569; this version posted May 11, 2021. The copyright holder for this preprint (which was not certified by peer review) is the author/funder, who has granted bioRxiv a license to display the preprint in perpetuity. It is made available under aCC-BY-NC-ND 4.0 International license.

Figure 5 - supplement 2. Regeneration of central fin regions. When internal sections of fin were excised and xanthophores adjacent to the wound marked by photoconversion, these cells or their progeny remained distally and failed to enter more proximal regions where erythrophores regenerated. Two examples of 4 total fish are shown. Dashed lines, proximal boundary of xanthophores with converted nucEosFP. Scale bar: $200 \mu \mathrm{m}$.
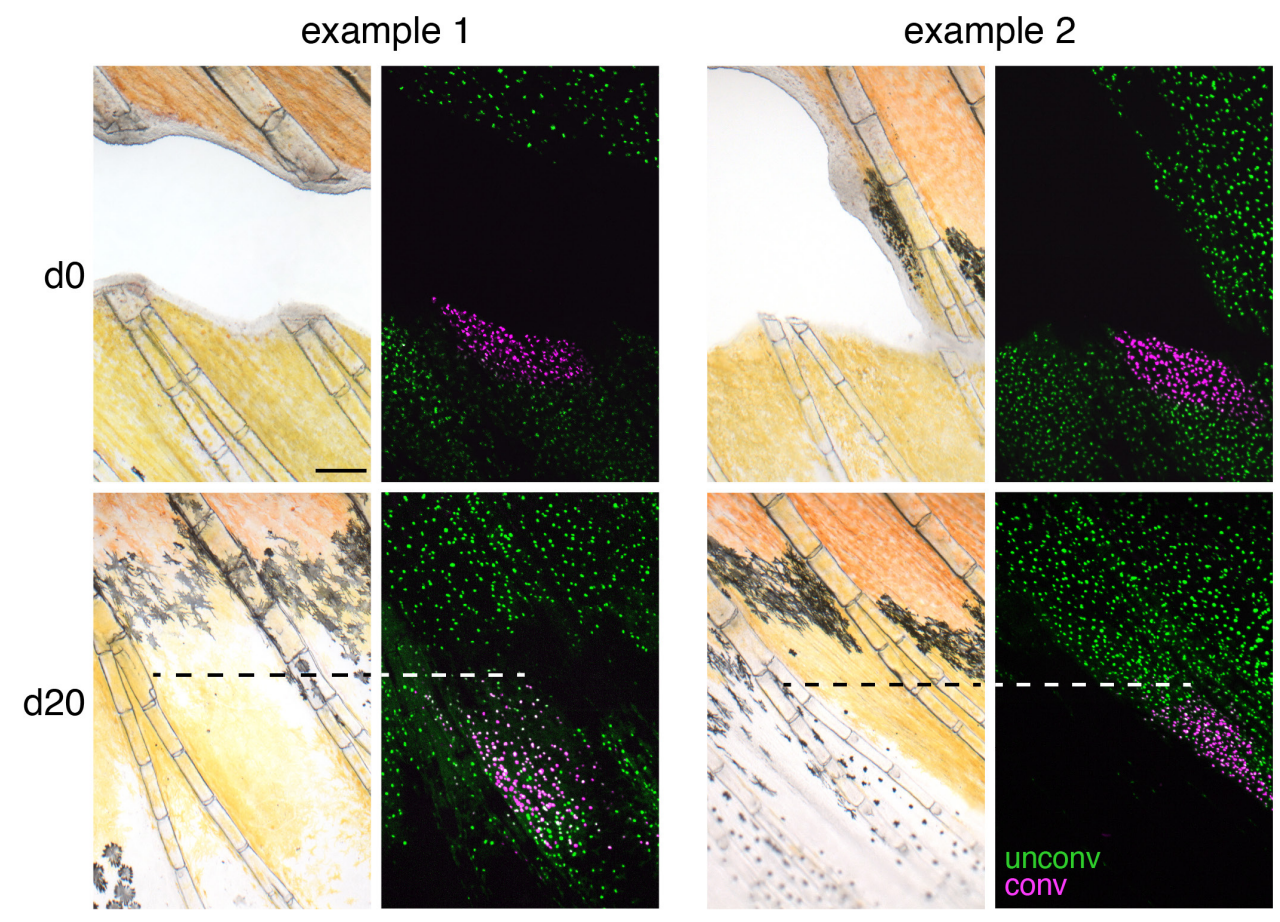
bioRxiv preprint doi: https://doi.org/10.1101/2021.05.11.443569; this version posted May 11, 2021. The copyright holder for this preprint (which

was not certified by peer review) is the author/funder, who has granted bioRxiv a license to display the preprint in perpetuity. It is made available under aCC-BY-NC-ND 4.0 International license.

Figure 6. Differential gene expression in fin regions with erythrophore and xanthophores. (A) Volcano plot of detected transcripts. Yellow-orange and red points indicate transcripts more abundant in xanthophore and erythrophore-cointaining regions, respectively $(q \leq 0.05)$. Grey points, transcipts not significantly different in abundance between regions. (B) Heat maps illustrating differential expression of selected loci across fin regions and replicate libraries. Genes with names in bold had phenotypes affecting erythrophore pigmentation.
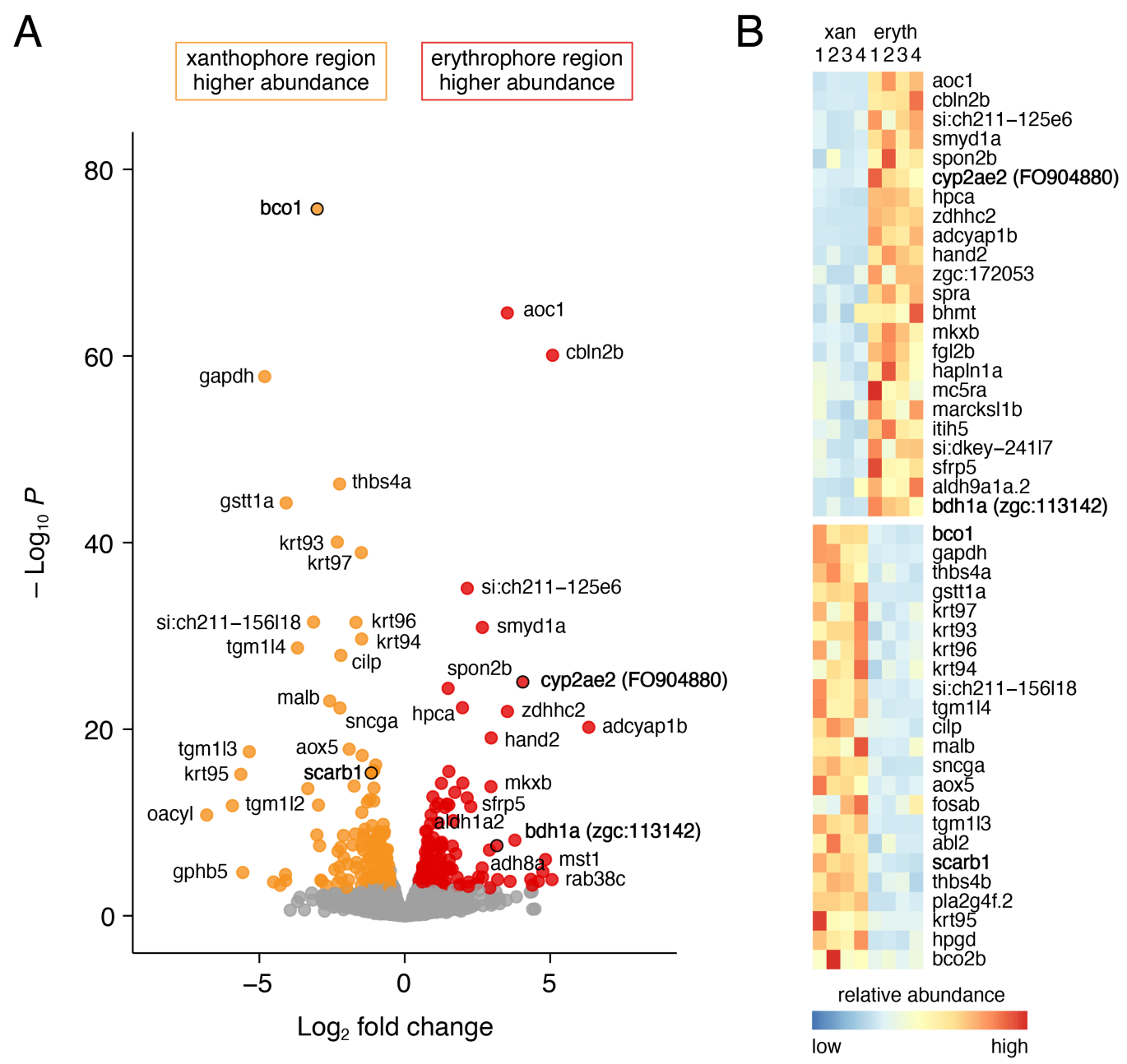
Figure 7. Wild-type pigment composition and mutant phenotypes. (A) Wild-type fin and carotenoid profile, showing carotenoid absorbance at $455 \mathrm{~nm}$ in adult male proximal tissue (red) and distal tissue (yellow). Numbers indicate different carotenoid species, with the most abundant ketocarotenoid in erthrophore-containing tissue being astaxanthan (peak 3; Figure 1A; Figure 7figure supplement $\mathbf{1}$ ). (B) Homozygous scarb1 mutants lacked red and yellow coloration and carotenoids were not detectable. (C) Homozygous mutant phenotypes of genes targeted from RNASeq comparisons. cyp2ae2 and bdh1a mutants were deficient for red color and astaxanthin. bco1 mutants had reduced red and yellow coloration and carotenoids. (D) Densities of erythrophores and xanthophores differed across backgrounds (Overall ANOVA background $\mathrm{x}$ region interaction, $F_{1,35}=19.01, P<0.0001$ ); means of groups not sharing the same letter differed significantly from one another $(P<0.05)$ in Tukey-Kramer post hoc comparisons. Each point represents the mean of densities measured in 3 regions of $4 \times 10^{-2} \mathrm{~mm}^{2}$ in proximal or distal regions with erythrophores or xanthophores, respectively, in each 39 total fish. (E) Ratios of red to green autofluorescence for cells found within proximal erythrophore containing regions (red filled points) and distal xanthophore containing regions (yellow filled points) of wild-type males and females compared to mutant males. In the wild-type, erythrophores and xanthophores were segregated into different populations in R/G color space, though differences in females were less marked. In males of each mutant, R/G ratios of erythrophores were reduced compared to wild-type, and lesser reductions were evident in xanthophores (ANOVA, genotype $\mathrm{x}$ region interaction, $F_{4,736}=310.82, P<0.0001$, after controlling for significant main effects and variation among individuals; $N=760$ cells total from 5 individuals of each background). (F) Wild-type males and females, and mutant males, differed in total visible pigment, as measured by diameters of contracted pigment granules following epinephrine treatment (Saunders et al., 2019). (ANOVA, background $x$ region interaction, $F_{4,736}=76.25, P<0.0001$, with significant main effects and variation among individuals; diameters were In-transformed for analysis to control for increasing residual variance with means.). Plots show means $\pm 95 \%$ confidence intervals. Scale bar: $50 \mu \mathrm{m}$. 
bioRxiv preprint doi: https://doi.org/10.1101/2021.05.11.443569; this version posted May 11, 2021. The copyright holder for this preprint (which

was not certified by peer review) is the author/funder, who has granted bioRxiv a license to display the preprint in perpetuity. It is made available under ACC-BY-NC-ND 4.0 International license.

\section{Figure 7}

A

B
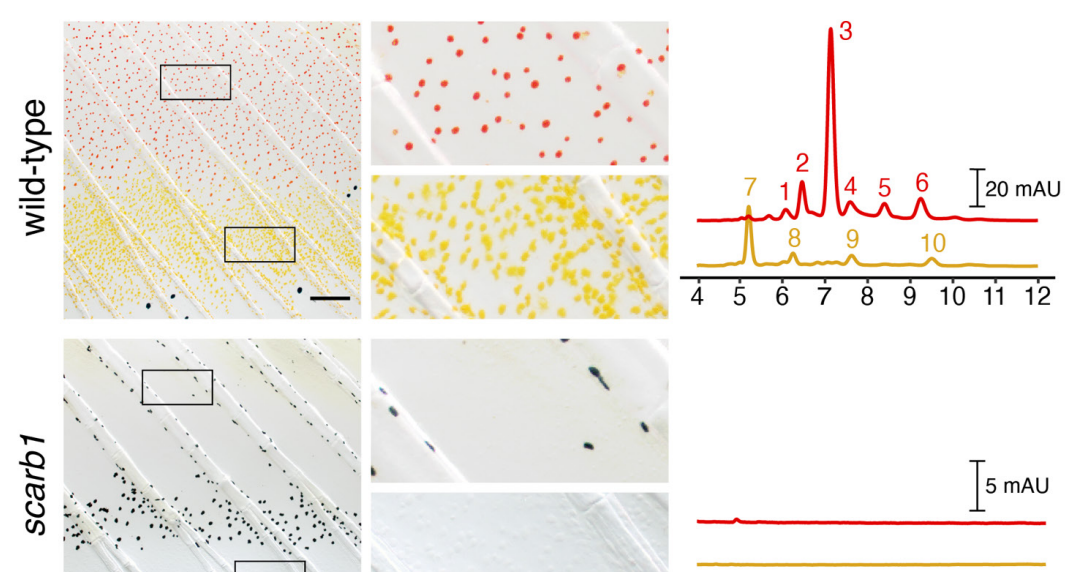

C
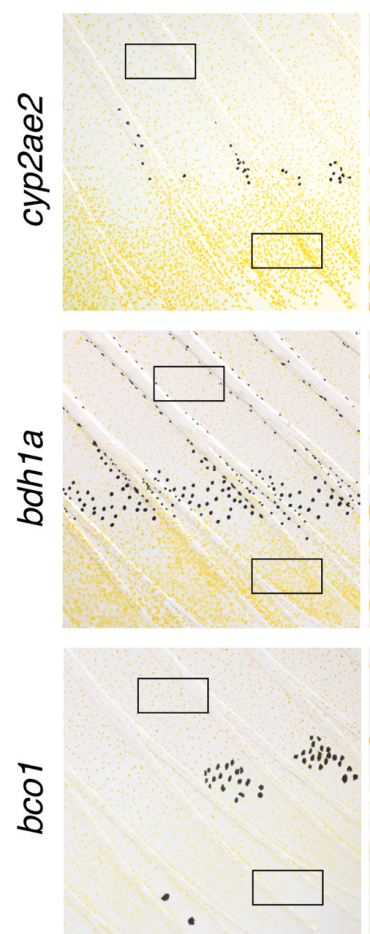
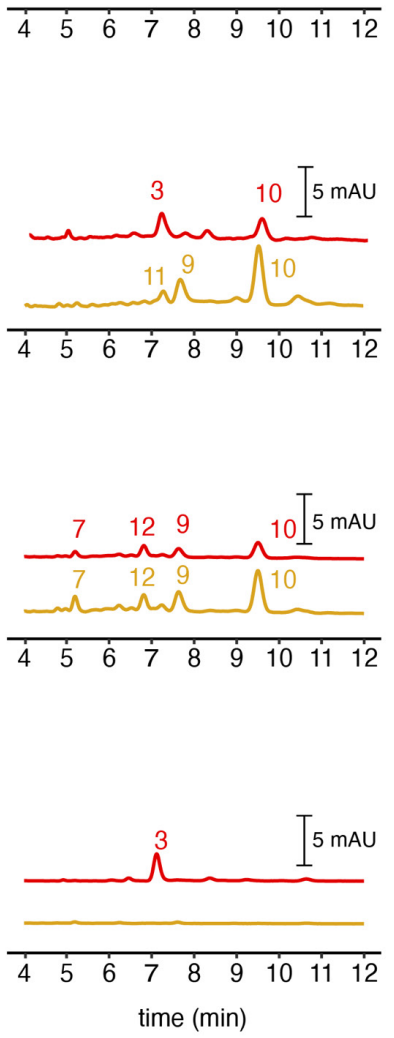

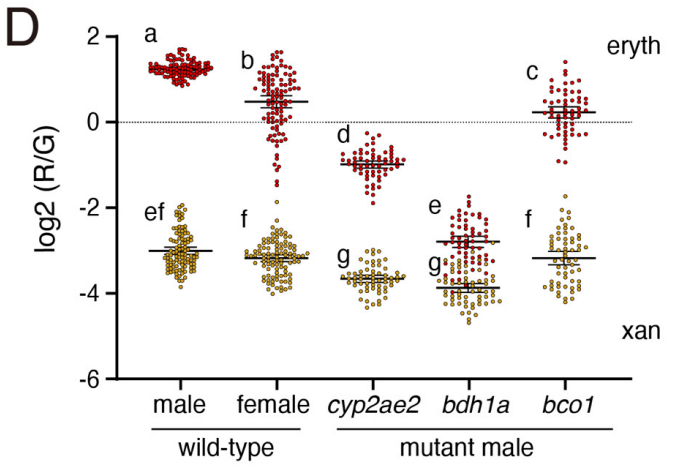

E
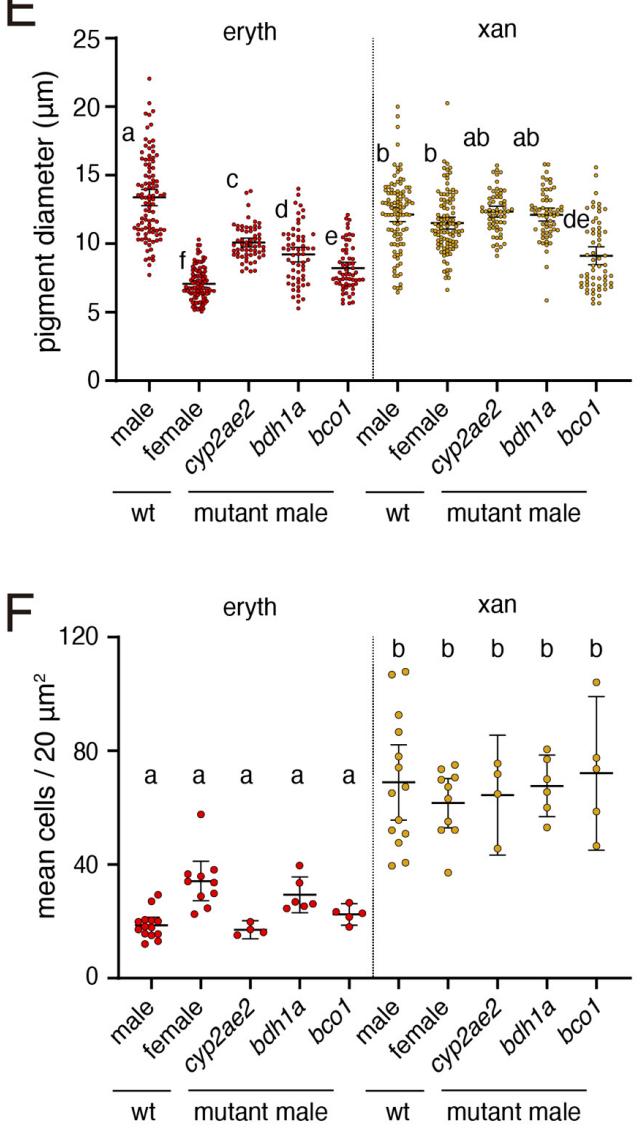
bioRxiv preprint doi: https://doi.org/10.1101/2021.05.11.443569; this version posted May 11, 2021. The copyright holder for this preprint (which

was not certified by peer review) is the author/funder, who has granted bioRxiv a license to display the preprint in perpetuity. It is made available under aCC-BY-NC-ND 4.0 International license.

Figure 7-figure supplement 1. Characterics of carotenoid absorbance spectra.

Representative normalized UV-Vis absorbance spectra of the major peaks in the carotenoid profiles of red and yellow fin portions of wild-type and various mutant D. albolineatus (Figure 7). Peaks 1-6 have a single relatively long-wavelength absorbance peak that is typical of extended conjugated system of C4-ketocarotenoids, including astaxanthin (Peak 3). Peaks 7-12 have multiple smaller peaks characteristic of xanthophyll carotenoids that do not have C4-keto groups contributing the conjugated system, including zeaxanthin (Peak 10).
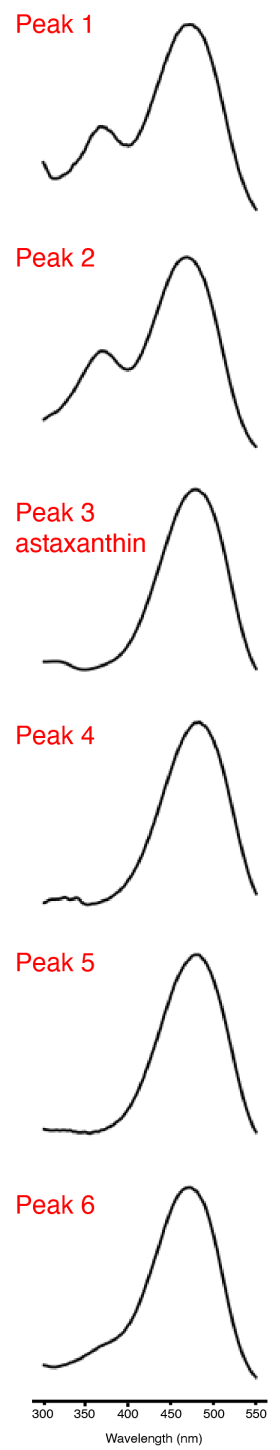
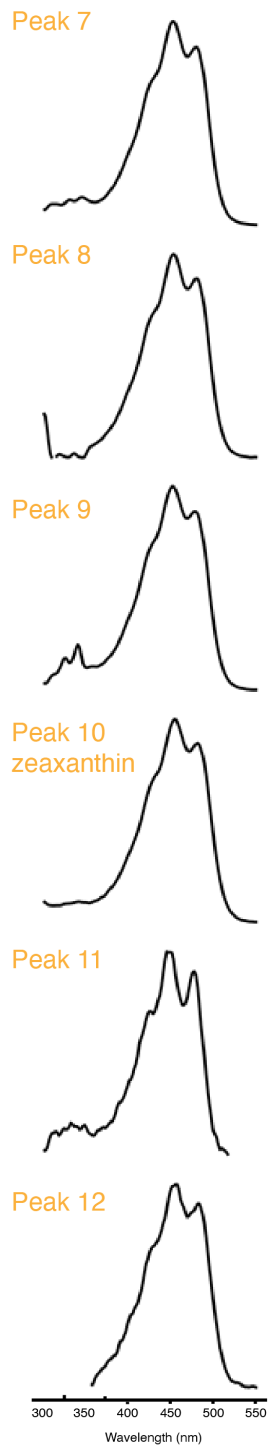
Figure 7-figure supplement 2. Mutant lesions recovered, presence of pteridines, and mosaic phenotype of bco1. (A) Alleles induced by CRISPR/Cas9 targeting of candidate genes. gRNA sequences in red. PAM sequences in blue. Dashed lines indicate missing nucleotides. (B) Fish mutant for scarb1 lacked visible red or yellow color but contained pteridines detectable by autoflourescence under ultraviolet illumination following treatment with dilute ammonia (Odenthal et al., 1996). Pteridine autofluorescence was not present in a xanthophore and erythrophore deficient mutant for colony stimulating factor 1 receptor a (csf1ra) (Lewis et al., 2019), which functions cellautonomously to promote xanthophore development in zebrafish (Parichy et al., 2000; Parichy and Turner, 2003). (C) Carotenoid pigments were mosaic in F0 fish injected with CRISPR/Cas9 targeting bco1. Patches of presumptively wild-type orange cells are outlined. Scale bar: $200 \mu \mathrm{m}$.

A

\begin{tabular}{|c|c|c|}
\hline 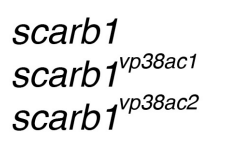 & $\begin{array}{l}\text { AAGGCCCATGGTGATCCAGAGAGGGCCGTAT } \\
\text { AAGGCCCAaGG --:---'CCGTAT } \\
\text { AAGGCCCATG --TGATCCAGAGAGGGCCGTAT }\end{array}$ & $\begin{array}{l}\text { wild-type } \\
-13 \text { bp } \\
-1 \text { bp }\end{array}$ \\
\hline $\begin{array}{l}\text { cyp2ae2 } \\
\text { cyp2ae2 }^{\text {vp39ac1 }}\end{array}$ & $\begin{array}{l}\text { CCTTCCСTCTGCCTATTGTTGGAAACGTGTT } \\
\text { CCTTCCCTCTGCCTATTGTTGG------CTATT }\end{array}$ & $\begin{array}{l}\text { wild-type } \\
-5 \mathrm{bp}\end{array}$ \\
\hline $\begin{array}{l}\text { bdh1a } \\
\text { bdh1a }\end{array}$ & $\begin{array}{l}\text { TACTCCACTCCGTCTCGCCCCAGTCACTGAT } \\
\text { TACTCCACT- }\end{array}$ & $\begin{array}{l}\text { wild-type } \\
-19 \mathrm{bp}\end{array}$ \\
\hline $\begin{array}{l}b c 01 \\
b c 01^{v p 41 a c 1} \\
b c 01^{v p 41 a c 2}\end{array}$ & 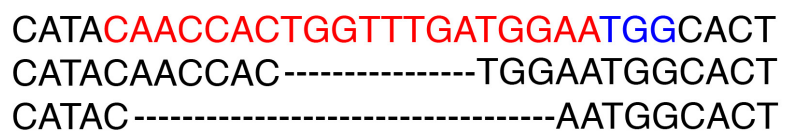 & $\begin{array}{l}\text { wild-type } \\
-8 \text { bp } \\
-17 \text { bp }\end{array}$ \\
\hline
\end{tabular}

B

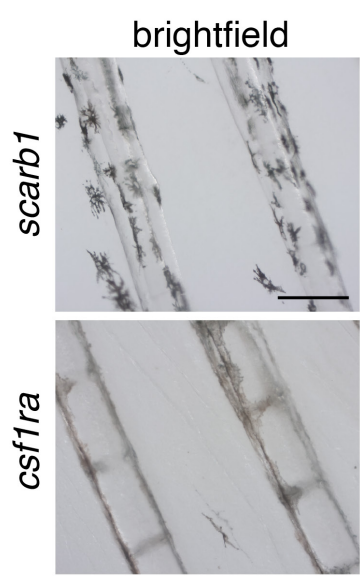

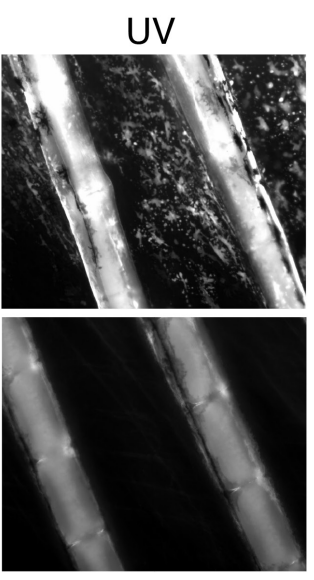

C

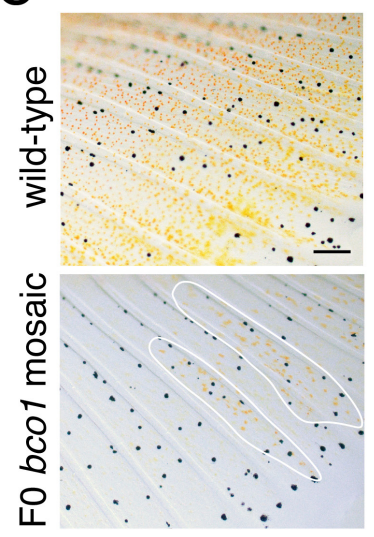


Figure 7-figure supplement 3. Expression, genomic location and additional phenotypes of genes contributing to red coloration. (A) RT-PCR of isolated pigment cells confirms expression by erythrophores of cyp2ae2, bdh1, and scarb1, and at low levels, bco1 (X, xanthophores; E, erythrophores; M, melanophores; S, skin; RT-, negative control without reverse transcriptase). (B) Genomic context of cyp2ae2 (FO904880.1) in D. rerio GRCz11 (Ensembl Release 103), showing major transcripts (green) and associated coding sequence (tan). (C) Later adult pigment cell and body phenotypes of wild-type compared to cyp2ae2 and bdh1a mutants. Scale bar: $4 \mathrm{~mm}$ (top); 200 $\mu \mathrm{m}$ (middle); $50 \mu \mathrm{m}$ (bottom).

A

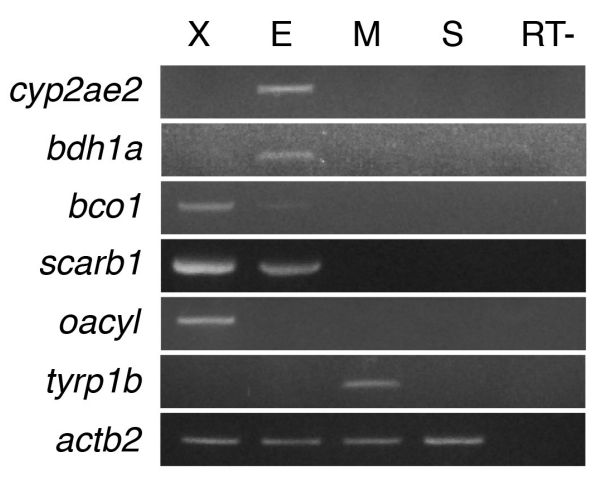

$\mathrm{B}$

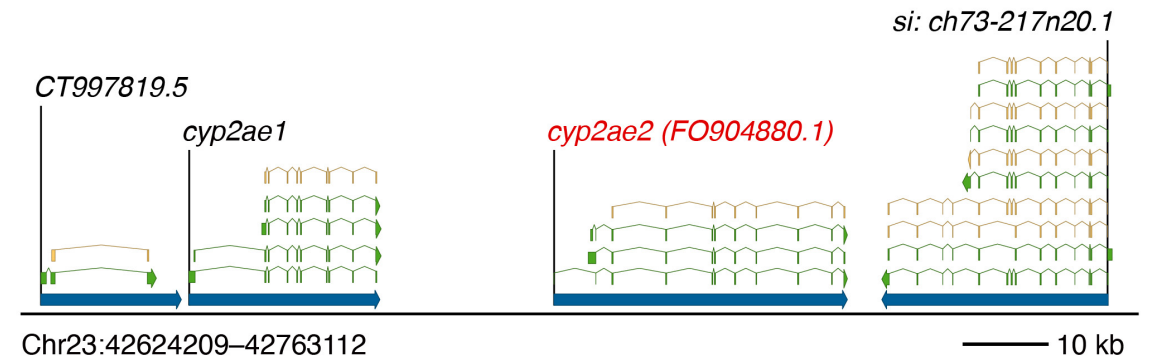

C

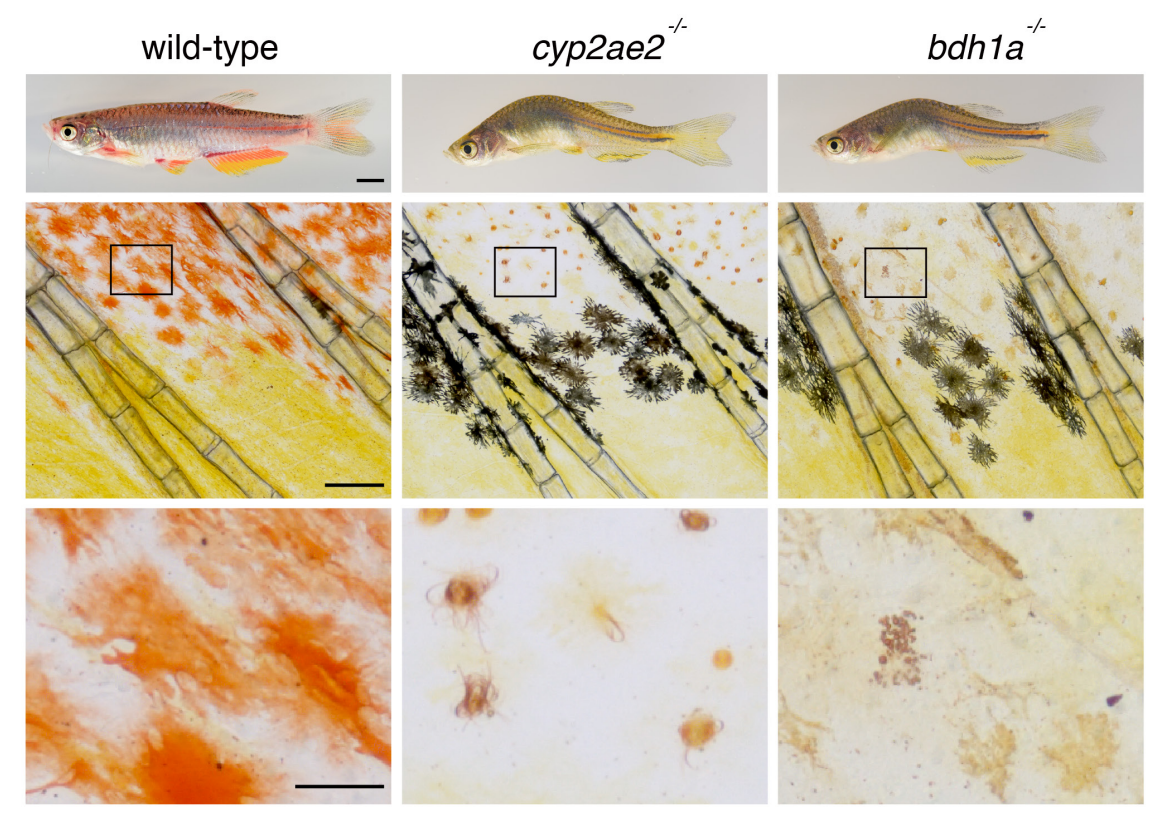


bioRxiv preprint doi: https://doi.org/10.1101/2021.05.11.443569; this version posted May 11, 2021. The copyright holder for this preprint (which

was not certified by peer review) is the author/funder, who has granted bioRxiv a license to display the preprint in perpetuity. It is made available under aCC-BY-NC-ND 4.0 International license.

Supplementary File 1-Tables of RNA-Seq analyses, reagents, and HPLC retention times. 